\title{
Planform evolution of deltas with graded alluvial topsets: Insights from 3D tank experiments, geometric considerations, and field applications
}

\author{
TETSUJI MUTO*, RYUJI FURUBAYASHI†, ARTI TOMER*, TOMOYUKI SATO $\ddagger$, \\ WONSUCK KIM, HAJIME NARUSE $₫$ and GARY PARKER** \\ *Department of Environmental Science, Nagasaki University, Nagasaki 852-8521, Japan \\ (E-mail: tmuto@nagasaki-u.ac.jp)
}

†Chuoh Consultants Co., Ltd, Nagono 2-11-23, Nishiku, Nagoya 451-0042, Japan

$\ddagger$ Geological Survey of Japan, AIST, Tsukuba 305-8567, Japan

$\S$ Department of Geological Sciences, University of Texas at Austin, 1 University Station C9000, Austin, TX 78712-025, USA

\Department of Geology and Mineralogy, Kyoto University, Kitashirakawaoiwake-cho, Sakyo-ku, Kyoto 606-8502, Japan

**Department of Civil \& Environmental Engineering and Department of Geology, University of Illinois, 205 N Mathews Ave, Urbana, IL 61801, USA

\section{ABSTRACT}

The profile of a river that conveys sediment without net deposition and net erosion is referred to as 'graded' with respect to vertical aggradation of the river segment. Three experimental series, designed in terms of the autostratigraphic view of alluvial grade, were conducted to clarify the diagnostic spatial behaviour of graded alluvial-deltaic rivers: an R series, which utilized a moving boundary setting with a stationary base level; an F series in a fixed boundary setting with a stationary base level to produce 'forced grade'; and an M series in a moving boundary setting with constant base level fall to produce 'autogenic grade.' The results of the three experimental series, combined with geometrical modelling of the effects of basin water depth and other experimental data, suggest the following: (1) in a graded alluvial-deltaic system, lateral shifting and avulsing of active distributary channels are suppressed regardless of whether the downstream boundary of the deltaic system is fixed; (2) in a delta with a downstream-fixed boundary, the graded streams are stabilized within a valley that is incised in the axial part of the delta plain, whereby the alluvial plain outside the valley is abandoned and terraced; (3) in moving boundary settings, the graded river simply extends basinward as a linearly elongated channel-and-lobe system without cutting a valley; and (4) a modern forced-graded alluvial river is most likely found in a valley incised into a fan delta in front of very deep water, and the stratigraphic signal of fossil autogenic-graded rivers will be 
found in deltaic successions that accumulated in the outer to marginal areas of deltaic continental shelves during sea level falls. This renewed autostratigraphic view of alluvial grade suggests a thorough reconsideration of the conventional understanding that an alluvial river feeding a progradational delta is graded with a stationary base level.

Keywords: alluvial river, autostratigraphy, base level, delta, experiment, grade, sea level

\section{INTRODUCTION}

The profile of a river that conveys sediment without net deposition and net erosion is referred to as 'graded' with respect to the vertical aggradation of the river segment. Grade is thus the incarnation of a dynamic equilibrium state of the river in terms of the sediment balance. The concept of grade, which was originally advocated by Gilbert (1877), is typically presented as the long-term, equilibrium state of a river system that is subject to steady external forcing by a stationary base level (Davis, 1902; Green, 1936; Kesseli, 1941; Leopold \& Bull, 1979; Posamentier \& Vail, 1988; Thorne \& Swift, 1991; Johnson \& Beaumont, 1995; Holbrook et al., 2006), with special emphasis on the rivers’ adjustments in slope (Mackin, 1948; Schumm, 1977).

A correct understanding of grade is fundamental to the morphodynamics, sedimentology and geology of river deltas because grade represents the critical condition that discriminates between aggradational and degradational regimes in a river system, and because grade is the key to the exploration of intrinsic river responses to base level forcing. Conventional notions in geology suggest that the stratigraphic responses of an alluvial river to base level changes are controlled by the graded profile of the river, which is believed to limit the vertical extent of subaerial accommodation (e.g. Posamentier et al., 1988; Posamentier \& Allen, 1999). Sequence stratigraphy, together with ancestral concepts that were advocated in the 1960s and earlier, has been developed on the assumption that (1) rivers basically aggrade in response to base-level rise and degrade in response to base-level fall, and (2) grade is the final, stable state of a river system that is attained through an equilibrium response to a stationary base level (Posamentier \& Vail, 1988; Thorne \& Swift, 1991; Holbrook et al., 2006). For the latter concept, the equilibrium response refers to a type of response by which a steady stratigraphic configuration arises from steady dynamic external forcing or static external forcing (Muto \& Steel, 2014).

Recent studies of alluvial-deltaic evolution as a moving boundary problem have brought a drastic revision of the grade concept: (1) the feeder alluvial river can become graded only 
during base-level fall (Nummedal et al., 1993; Leeder \& Stuart, 1996; Muto \& Swenson, 2005b; Nijhuis et al., 2015); (2) the time patterns of base-level fall that allow the river to become graded depend on the basin configuration (Muto \& Steel, 2014); and (3) alluvial rivers can be graded both allogenically and autogenically (Muto \& Swenson, 2006). This set of novel notions is referred to as the 'autostratigraphic view of grade' (Muto et al., 2007; see below) and has been derived largely from 2D geometrical modelling and corroborative narrow flume experiments. However, some critical questions remain unsolved, such as how a graded river behaves in a 3D spatial setting where the depositional system is free from lateral confinement, what planometric geometry and channel patterns could be intrinsic to a graded river, and what stratigraphic and/or geomorphic evidence is left by a graded river in geological records. Although a graded river, by definition, leaves no deposits and has no erosional features, no established rationale exists to deny the possibility that indirect signs of its spatial and temporal presence can be detected from the landscape or the strata.

The objective of the present study is to extend what has been learned in 2D studies to the 3D modelling of alluvial grade through 3D tank experiments, although the primary focus here is on the macroscopic behaviour of graded streams in the planar surface of an alluvial delta plain. As shown below, the results of 3D tank experiments, combined with simple geometrical modelling and existing notions that were obtained from a previous series of experiments, demonstrate that 3D graded alluvial-deltaic systems can behave in distinctive spatial patterns that will be identifiable in both modern and ancient river deltas. This study presents a new view of alluvial grade that revises the understanding of the intrinsic responses of alluvial-deltaic systems to base level forcing.

In the following argument, the terms 'alluvial plain', 'alluvial topset' and 'delta plain' mean basically the same thing, but from different points of view or emphasis (e.g. process, topography, part of the delta). These can be used interchangeably.

\section{AUTOSTRATIGRAPHIC VIEW OF ALLUVIAL GRADE}

Autostratigraphy is the stratigraphy that is generated by large-scale autogenic processes, based on the full recognition of (1) the non-equilibrium behaviour of depositional systems in response to steady external forcing and (2) the general lack of an equilibrium configuration of depositional systems (Muto et al., 2007). Non-equilibrium response is a type of response by which steady dynamic forcing results in an unsteady stratigraphic configuration for the depositional system, or by which unsteady dynamic forcing is responsible for a steady stratigraphic configuration (Muto \& Steel, 2014). It is a non-equilibrium response rather than 
an equilibrium response that generally holds under steady external forcing. Although an equilibrium response is physically possible, as noted before (Muto \& Swenson, 2006), and is also illustrated in the present study, ignoring the non-equilibrium response can lead to a serious misinterpretation of stratigraphic records.

In autostratigraphy, 'autogenic' (noun form: autogenesis) refers to the origin of stratal and/or geomorphic features that arise as stratigraphic responses despite steady dynamic external forcing. Conversely, 'allogenic' (noun form: allogenesis) refers to stratigraphic and/or geomorphic responses that are generated because of unsteady dynamic external forcing. The conventional idea with respect to these terms is that autogenesis merely operates at sub-depositional system scales and that only allogenesis is directly relevant to the larger-scale architecture of basin fill (Catuneanu, 2006). This idea is based on the implicit belief that autogenesis is always associated with responses of the depositional system that are local (i.e. a small part of the system), stochastic and cyclic, thus missing another important type of autogenesis that is global (i.e. affecting the entire system), deterministic and non-cyclic (Muto et al., 2007).

Two-dimensional experiments performed over the past decade have clarified that alluvial grade can be attained by aggradation or degradation (see below), for either non-equilibrium or equilibrium responses in a moving boundary system, where the landward and basinward boundaries of the depositional system are not fixed to particular points on the basement surfaces, but requires base-level fall (Muto \& Swenson, 2006). Thus, the critical condition for discriminating between aggradational and degradational regimes of alluvial systems is not a stationary base level but a continuous fall in base level. Alluvial rivers can, in principle, continue to aggrade throughout the duration of base-level fall unless the base level falls below the grade curve (Petter \& Muto, 2008).

A rigorous stratigraphic criterion to judge if an alluvial river in a deltaic setting is graded is the lack of an alluvial topset deposit despite no significant erosional features in the delta profile. An alternative, easier method is to monitor the behaviour of the alluvial-basement transition (ABT), i.e. the upstream end of the alluvial reach (Fig. 1). The alluvial river is aggrading if the ABT is steadily migrating upstream and is degrading if the ABT is steadily migrating downstream. Thus, a condition for the river to remain graded is for the ABT to remain stationary. The sustained standstill of the ABT is thus a diagnostically necessary condition to achieve alluvial grade. This simple method is adopted in the present experimental study, where a stratigraphic cross section was not available.

Previous experiments that were conducted under aggradational (i.e. non-graded) 
conditions show that even with constant sediment supply $Q_{\mathrm{s}}$ and constant water discharge $Q_{\mathrm{w}}$, alluvial rivers can significantly change their slopes with time and space, which reflects autogenic events of sediment storage and release (e.g. Kim \& Jerolmack, 2008; Reitz \& Jerolmack, 2012). In contrast, a graded alluvial river that is produced in 2D experiments produces a linear longitudinal profile with a uniform slope because $Q_{s} / Q_{\mathrm{w}}$ is spatially constant (Muto \& Swenson, 2005a). In the present 3D experiments, any clear autogenic events of sediment storage and release are not recognized while the alluvial river is graded, although local deposition and erosion can occur even during a graded stage (see below). Thus, the present modelling assumes that the mean alluvial slope does not significantly change with time and space. It is also assumed that $Q_{\mathrm{s}}$ and $Q_{\mathrm{w}}$ at the ABT are always constant.

Under the moving boundary condition, alluvial grade can arise in two different ways depending on the geomorphic conditions and time patterns of base-level fall, for which the alluvial slope $\alpha$ and basin floor slope $\phi$ are particularly influential (Figs. 1A, B). These two slope parameters affect the fate of sediment that has bypassed the alluvial reach and accumulates basinward to the shoreline, which then feeds back to the feeder alluvial river (Petter \& Muto, 2008).

Where $\alpha<\phi$, the delta progrades into water that progressively deepens basinward (Fig. 1A). For the alluvial river to retain a complete sediment-bypass system, the base level is required to fall at a decelerating rate in a particular pattern (Muto \& Swenson, 2005a). Thus, the alluvial grade that is attained under this slope condition is an allogenic one that arises from a non-equilibrium response to unsteady external forcing ('allogenic grade'). If the base level instead falls at a constant rate in this slope setting, the river aggrades during an early stage but later degrades by an autogenic non-equilibrium response (Swenson \& Muto, 2007).

Where the basin slope is equal to the alluvial slope $(\alpha=\phi)$, the water depth in front of the prograding delta does not change over time, provided that the base level continues to fall at a constant rate (Fig. 1B). This slope condition is possible where a delta progrades above a drowned alluvial plain or an antecedent graded alluvial reach that was built during base-level fall or the lowstand of a previous cycle. Under this topographic condition, alluvial grade is autogenically attained and sustained by an equilibrium response to the steady base-level fall ('autogenic grade'; see Muto \& Swenson, 2006). The rate of base-level fall ( $\left.R_{\mathrm{blf}}\right)$ simply functions to determine the set thickness of the prograding deposit $\left(h_{\text {set }}\right)$ and never affects whether grade is attained as long as the rates of base-level fall and sediment supply per unit width $\left(q_{\mathrm{s}}\right)$ to the ABT are kept constant. The basin water depth right in front of the delta $(h)$ is 
controlled by $R_{\mathrm{blf}}$ and $q_{\mathrm{s}}$. When autogenic grade is attained, the following geometrical relationship holds:

$$
\begin{aligned}
& R_{\mathrm{pro}}=\alpha^{-1} R_{\mathrm{bff}} \\
& q_{\mathrm{s}}=h_{\mathrm{set}} R_{\mathrm{bff}} \sqrt{1+\alpha^{-2}}=h_{\mathrm{set}} R_{\mathrm{pro}} \sqrt{1+\alpha^{2}}=h R_{\mathrm{pro}}\left(\frac{\beta-\alpha}{\beta}\right) \\
& h=\frac{q_{\mathrm{s}}}{R_{\mathrm{bff}}}\left(\frac{\alpha \beta}{\beta-\alpha}\right)=\Lambda_{2 \mathrm{D}}\left(\frac{\alpha \beta}{\beta-\alpha}\right)
\end{aligned}
$$

where $R_{\text {pro }}$ is the rate of delta progradation averaged over the entire shoreline, $\beta$ is the delta's foreset slope, and $\Lambda_{2 \mathrm{D}}$ is the autostratigraphic length scale in two dimensions (Muto et al., 2007). Equation 2 indicates that when the feeder alluvial river is autogenically graded, the delta has a particular set thickness specified with $q_{\mathrm{s}}, R_{\mathrm{blf}}$ and $\alpha$. Thus, autogenic grade can be approached by aggradation if the existing delta set is thinner than $h_{\text {set, }}$ and by degradation in the opposite case (see also Muto \& Swenson, 2005b, 2006).

Where the alluvial slope is greater than the basin slope $(\alpha>\phi)$, the water depth in front of the delta decreases as it progrades with constant base-level fall, and the alluvial river eventually detaches from the seaward-receding shoreline and thus becomes non-deltaic (Petter \& Muto, 2008). In this slope setting, along with constant base-level fall and constant sediment supply, the river can never attain grade but can sustain alluvial aggradation.

If the downstream end of the depositional system is fixed, alluvial grade can forcibly be attained with a stationary base level ('forced grade'; Fig. 1C), just as for cases of a non-deltaic alluvial river that is dammed up with a downstream weir (Postma et al., 2008; Cantelli \& Muto, 2014; Bijkerk et al., 2016) and for a deltaic alluvial river that is perched on a 'shelf edge' at which the feeder flows simply dump the entire supplied sediment into very deep water (Parker, 1977; Kim et al., 2013). The attainment of alluvial grade in this downstream-fixed setting can be explained in terms of the effect of basin water depth, as discussed below. A fundamental difference between forced grade and autogenic grade is in the relationship with basin water depth in front of the delta: i.e. the attainment of forced grade requires the presence of very deep basin water, whereas for autogenic grade the basin water depth is not given a priori but depends on $R_{\mathrm{blf}}$ and $q_{\mathrm{s}}$ (thus $\Lambda_{2 \mathrm{D}}$; Eqs. 2, 3) and does not affect whether the topset alluvial river becomes graded.

Thus, alluvial grade can arise by three different mechanisms (Fig. 1): (1) forced grade, which is attained through an equilibrium response to the stationary base level in a downstream-fixed setting; (2) allogenic grade, which is attained through a non-equilibrium 
response to decelerating base-level fall in a moving boundary setting where $\alpha<\phi$; and (3) autogenic grade, which is attained through an equilibrium response to constant base-level fall in a moving-boundary setting where $\alpha=\phi$. The present experimental study excludes allogenic grade because its 3D attainment is technically difficult through available experimental methods, although this process is not impossible in principle.

\section{GRADE INDEX}

In the present 3D study of alluvial grade (particularly forced grade), a dimensionless number grade index $\left(G_{\text {index }}\right)$ is introduced to describe how close the alluvial river is to a graded state. The grade index is defined by

$$
\begin{aligned}
& G_{\text {index }}=\frac{1}{1+\chi\left(h_{*}\right)} \\
& h_{\star}=\frac{h}{\alpha x}
\end{aligned}
$$

where $h *$ is the dimensionless basin water depth; $\alpha$ is the tangent of the mean alluvial slope; $x$ is the delta plain radius (i.e. horizontal distance from the ABT to the shoreline); and $\chi(h *)$, a function of $h *$, denotes a dimensionless measurement of how much sediment that is supplied through the ABT is allocated in the delta's subaqueous part relative to the subaerial part, which is always given as unity. Thus, the right side of Eq. 4 expresses a ratio of the subaerial sediment allocation to the entire sediment allocation. Clearly, $G_{\text {index }}$ takes a value between 0 and 1: $\chi(h *)>>1$ and $G_{\text {index }} \sim 0$ for grade (i.e. perfect bypass of the supplied sediment to the delta's subaqueous slope), and $\chi(h *) \sim 0$ and $G_{\text {index }} \sim 1$ for perfect alluvial aggradation (i.e. no sediment accumulation basinward of the shoreline). The specific form of $\chi(h *)$ can vary depending on associated parameters, including the base level conditions and geometrical conditions of the delta and basin. $G_{\text {index }}$ is most valid when it is applied to a depositional system that is growing under an aggradational regime, and basically is not applicable to a degradational system.

In fact, $G_{\text {index }}$ can govern several basic aspects in terms of the spatial behaviour of the alluvial feeder system, as implied from simple geometrical modelling for the following hypothetical case: (1) the delta plain is attached to a vertical wall behind and has a central angle of $\lambda$ in radians; (2) the basin floor is horizontal with a constant water depth of $h$; (3) the base level remains stationary; and (4) the values of $Q_{s}$ and $Q_{\mathrm{w}}$ are constant (Fig. A1). Actually, these conditions have often been adopted in tank experiments (e.g. Kim et al., 2009; Powell et 
al., 2012; Reitz \& Jerolmack, 2012; Kim et al., 2013). If the overall geometry of the delta as specified by its angle parameters is retained during progradation, the following relationship holds (see Appendix 1 for derivation):

$$
\begin{aligned}
& G_{\text {index }}=\frac{1}{1+2 h_{\star}+\alpha h_{\star}^{2}} \\
& R_{\mathrm{pro}^{*}}=R_{\mathrm{agg}^{*}}=R_{\mathrm{mig}^{*}}=f_{\mathrm{A}^{*}}=\left(\tau_{\mathrm{A}^{*}}\right)^{-1}=\left(\tau_{\mathrm{s}^{*}}\right)^{-1}=\left(\tau_{\mathrm{r}^{*}}\right)^{-1}=G_{\text {index }}
\end{aligned}
$$

where $\alpha *=\alpha \beta^{-1}$, and $R_{\text {pro* }}, R_{\text {agg* }}, R_{\mathrm{mig}^{*}}, f_{\mathrm{A}^{*}}, \tau_{\mathrm{A}^{*}}, \tau_{\mathrm{s}^{*}}$, and $\tau_{\mathrm{r}^{*}}$ are non-dimensionalized values

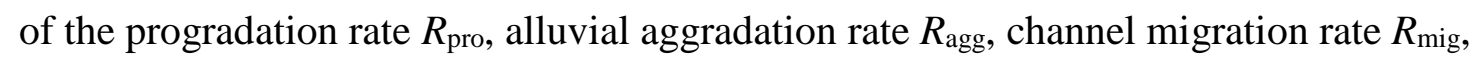
channel avulsion frequency $f_{\mathrm{A}}$, time scale for channel aggradation $\tau_{\mathrm{A}}$, time scale for channel migration $\tau_{\mathrm{s}}$, and recurrence period for a migrating channel $\tau_{\mathrm{r}^{*}}$, respectively. For the topographic setting considered, $\chi(h *)$ does not take a negative value $\left(2 h *+\alpha h *^{2}>0\right)$. Each dimensionless value is obtained by dividing the original value with the value of the case that basin water is very shallow (i.e. $h \sim 0$ ). $R_{\text {agg* }}$, for example, is given by

$$
R_{\mathrm{agg}}=\frac{R_{\mathrm{xgg}}}{R_{\mathrm{xgg}_{\mathrm{g} h-0}}}=\frac{1}{1+2 h_{\star}+\alpha h_{\star}^{2}}
$$

which means that $R_{\text {agg }}$ can be estimated as the product of $R_{\mathrm{xgg}_{h-0}}$ and $G_{\text {index }}$. From this point of view, $G_{\text {index }}$ also denotes the effects of the basin water depth upon the overall dynamics of the delta's distributary channels. Equations 6 and 7 suggest that the alluvial topset river of the delta approaches grade as $h *$ increases towards $+\infty$, and perfect aggradation as $h *$ decreases towards 0 . If the delta is unable to prograde basinward $\left(R_{\text {pro* }} \sim 0\right)$ because of very deep basin water in front $(h *>>1)$, then the delta plain does not aggrade $\left(R_{\mathrm{agg} *} \sim 0\right.$; i.e. the attainment of forced grade, $\left.G_{\text {index }} \sim 0\right)$, and its distributary channels do not migrate $\left(R_{\text {mig* }} \sim 0 ; \tau_{\mathrm{r}^{*}} \sim+\infty\right)$ and avulse $\left(f_{\mathrm{A}^{*}} \sim 0 ; \tau_{\mathrm{A}^{*}} \sim+\infty\right)$.

Equation 6 and 7 are based on a set of peculiar conditions and are not necessarily applicable to other settings, particularly to the settings that produce autogenic grade. Nevertheless, the equality relationship between the dimensionless rates in Eq. 7 is, at least partly, suggestive of the characteristic, planform behaviour of graded distributary channels, whether they are forced grade or autogenic grade, as shown below.

\section{TANK EXPERIMENTS}

Tank experiments were conducted to explore the spatial behaviour of a graded alluvial river under a basement condition that does not confine the delta's expansion to the transverse direction. Three series of experiments were conducted: the ' $R$ series' acts as a reference for 
the other two and was conducted in a moving boundary setting with a stationary base level (Runs R1, R2, R3); the 'F series' examines the attainment of forced grade in a fixed boundary system with a stationary base level (Runs F1, F2, F3, F4); and the 'M series' examines the attainment of autogenic grade in a moving boundary system with constant base level fall (Runs M1 and M2). All the experiments were conducted in tank facilities at Nagasaki University. The sediment that was used in all the runs was $0.2 \mathrm{~mm}$ uniform quartz sand (grain density $=2.63 \mathrm{~g} \mathrm{~cm}^{-3}$, bulk density $=1.52 \mathrm{~g} \mathrm{~cm}^{-3}$, porosity $=0.42$ ). During each run in all the series, the upstream sediment discharge $Q_{\mathrm{s}}$ and upstream water discharge $Q_{\mathrm{w}}$ were kept constant. Many previous tank/flume experiments that were performed to produce alluvial depositional systems show that the alluvial slope generally depends on $Q_{\mathrm{s}}$ and $Q_{\mathrm{w}}$ (Whipple et al., 1998; Van Dijk et al., 2009; Powell et al., 2012). Thus, the mean or overall alluvial slope that is adopted in each run of the present study is assumed to be retained during the entire period of the run. Although local alluvial slope can drastically change in response to autogenic events of sediment storage and release (Kim \& Jerolmack, 2008), the previous 2D experiments clearly indicate that graded alluvial rivers are spatially uniform and had a constant longitudinal slope that was specified with $Q_{\mathrm{w}}$ and $Q_{\mathrm{s}}$, which are then retained as long as the graded is sustained (Muto \& Swenson, 2005b).

Runs R1-3, F1-4 and M1 were conducted in the experimental tank 'Margi 2' (200 cm long $\times 100 \mathrm{~cm}$ wide $\times 70 \mathrm{~cm}$ deep), and Run M2 was conducted in 'Margi 4' (300 cm long $\times$ $600 \mathrm{~cm}$ wide $\times 55 \mathrm{~cm}$ deep). The experimental conditions are summarized in Table 1.

As noted above, the slope conditions (particularly $\alpha$ and $\phi$ ) affect the attainment and maintenance of alluvial grade. For the M series, the basin floor is required to have the same slope as the graded alluvial river. To achieve this set up, preliminary experiments for both Runs M1 and M2 were conducted to measure an alluvial slope at grade for a given set of $Q_{\mathrm{s}}$ and $Q_{\mathrm{w}}$ with the use of a downstream weir (Fig. 1C). The basin slope was then adjusted to be equal to the alluvial slope (i.e. $\alpha \sim \phi$ ). In the R series, the basin slope was chosen to more or less coincide with the alluvial slope (Table 1) to give a reference for the function of base level fall in the M series.

Plan view photos of the growing delta were taken every 30 seconds during each run. A primary measurement identified active shoreline segments on time-lapse images, i.e. the mouths of active distributary channels. Because distributary channels themselves are difficult to identify in photographic images because of clean water flow over the uniform sediment, our observations focused on detecting active channel mouths (i.e. active shoreline segments) that can be identified with ImageJ64 by comparing two successive images. The location of an 
active shoreline segment can be quantified through an analysis of the azimuth angles $\theta\left(0^{\circ} \leq \theta\right.$ $\leq 180^{\circ}$ ) at both ends of the segment that are measured from the initial source point, i.e. the intersection of an initial bedrock river with an initial shoreline, such that $\theta=90^{\circ}$ for due basinward and $\theta=0^{\circ}$ and $\theta=180^{\circ}$ for the shoreline at either end of the two sides (Fig. 2). Pairs of measured values of $\theta$ were plotted against time $t$, and each segment was expressed as a horizontal bar with a width that was specified by the difference between values of $\theta$ (e.g. $\theta_{2}-\theta_{1}, \theta_{4}-\theta_{3}, \theta_{6}-\theta_{5}$ in Fig. 2). By plotting $\theta-t$ data for the entire run, the trajectories of active shoreline segments can be characterized. Another primary task was to measure the upstream horizontal distances of the ABT from the initial source point in centimetres, and to assess whether the river was graded.

\section{R Series}

\section{Experimental Method and Design}

A 90-cm wide rigid plate with a constant longitudinal slope was placed inside Margi 2. Sediment and water were supplied from the upstream end of a steeper 'hinterland' plate (slope $\gamma=0.364$, in tangent), through a sandglass-like funnel (potential error $<2 \%$ ) and a tube that was connected to multiple weirs (potential error $<0.5 \%$ ), respectively. These materials bypassed for some distance over the non-erodible bedrock basement (i.e. the plate surface), and an isolated conical fan delta was built where the feeder streams met the surface of the standing water, i.e. the base level. The initial shoreline was located where the two plates were joined.

The subaqueous basement (basin floor) had a constant slope $\phi$ of 0.231 (in tangent). $Q_{\mathrm{s}}$ was $1.178 \mathrm{~cm}^{3} \mathrm{~s}^{-1}$, including the pore space, and was paired with a $Q_{\mathrm{w}}$ of $3.81-6.50 \mathrm{~cm}^{3} \mathrm{~s}^{-1}$. During the entire period of each run, the water surface level inside the tank remained constant.

\section{Experimental Results}

As shown in sequential images of Run R1 (Fig. 3), the delta was built during the initial stage by sheetflow that covered the entire alluvial surface, and sediment was simultaneously added to the entire deltaic shoreline $\left(\theta=0-180^{\circ}\right.$; Fig. 3A). As the alluvial surface progressively expanded, the sheetflow gradually transformed into distributary stream channels, whereby active shoreline segments took scattered positions but incessantly migrated laterally and never stayed at a particular position for a period of more than a few tens of seconds (Figs. 3B, C). Occasionally, only a single, relatively large channel was present on the delta plain, but 
at other times, multiple small distributary channels were present there. These two states of the alluvial feeder system alternated with each other, and this pattern was closely analogous with the observations in the tank experiments by Van Dijk et al. (2009). The experiment was conducted for two hours, during which period the delta simply continued to expand not only basinward by progradation but also landward by alluvial aggradation. During the entire run, the ABT tended to migrate upstream with minor basinward-landward oscillations (Fig. 4A).

Figure 4 shows the trajectories of the active shoreline segments and ABT that were obtained from the three runs of the R series. Runs R2 and R3 were conducted with lower and higher water discharges than Run R1, respectively (Table 1). Despite the significant difference in $Q_{\mathrm{w}}$, the trajectories of the active shorelines were largely the same as those from Run R1, which shows that the active shorelines continued to migrate laterally and occasionally avulsed. The upstream migration of the ABT was consistently sustained, as observed in Run R1.

The topographic setting for the R series runs is significantly different from the one that is assumed for Eq. 6 from the point-of-view that (1) the hinterland basement is not vertical but gently inclined, (2) the basin floor landward of the overfall is not horizontal but gently tilting basinward, and thus (3) the basin water depth in front of a delta is not spatially uniform but increases basinward proportional to $x$. With these conditions, the dimensionless basin water depth and grade index are constant (for derivation, see Appendix 2):

$$
\begin{aligned}
& h_{*}=\frac{\beta \phi}{\alpha(\beta-\phi)} \\
& \kappa=\chi\left(h_{*}\right)=\mathrm{const}>0 \\
& G_{\text {index }}=\frac{1}{1+\kappa}
\end{aligned}
$$

Given the measured geometrical parameters of the runs, $h *=1.59-1.97$ and $\kappa=1.06-2.09$ as estimated by numerical simulation, whereby $G_{\text {index }}=0.323-0.486$.

\section{Interpretation}

Because the ABT tended to migrate upstream and did not come to a sustained standstill, alluvial channels on the deltaplain consistently aggraded and never attained grade. While the

alluvial system was non-graded with substantial aggradation, the alluvial channels incessantly migrated laterally and often avulsed. In a relatively short time interval, active channels regressed to previous locations, such that the deltaic shoreline on the whole tended to retain 
its closely isotropic, arcuate configuration in plan view. The active alluvial aggradation is directly indicated by the $\kappa$ values, which suggest that a half to a third of the sediment that was supplied through the ABT was consumed for alluvial aggradation.

\section{F Series}

\section{Experimental Method and Design}

The design of the F series runs, which generated an alluvial river at forced grade, was basically the same as the R series runs. The basin floor slope $\phi$ was $0.0871-0.132$, whereas the hinterland slope $\gamma$ was 0.364 (Table 1 ). In the F series runs, however, the basinward end of the 'shelf' was aligned with a submerged overfall so that the delta could not prograde beyond this line (Figs. 1C, 5). This distinct drop in the basement functioned as a type of downstream weir against which the alluvial topset river readily attained grade (Cantelli \& Muto, 2014). Four runs were conducted under slightly different conditions (Table 1). The shelf was $20 \mathrm{~cm}$ in width (dip direction) and had a constant slope $(\phi) . Q_{\mathrm{s}}$ was $1.178 \mathrm{~cm}^{3} \mathrm{~s}^{-1}$, including the pore space, and was paired with a $Q_{\mathrm{w}}$ of 3.81-4.63 $\mathrm{cm}^{3} \mathrm{~s}^{-1}$. Through out the duration of each run, the water surface level inside the tank remained constant.

The F series runs were somewhat analogous to the ones that were conducted by Kim et al. (2013), for which a delta was built with a vertical rigid plane in the rear such that the delta's ABT was always fixed on the vertical plane and thus was restricted in horizontal movement. Because of this peculiar topographic setting, judging whether the feeder alluvial river became graded was difficult. Apart from consideration of the ABT, the behaviour of the alluvial channels in the present runs (see below) was quite similar to that observed in the experiments by Kim et al. (2013).

\section{Experimental Results}

Figure 5 shows sequential photo images of Run F1. No significant differences from the R series runs were apparent until the delta toe reached the shelf edge (i.e. overfall): (1) the feeder alluvial system developed first as sheetflow and then as distinct stream channels, which incessantly migrated laterally and frequently avulsed; (2) the ABT tended to migrate landward; and (3) multiple small channels alternated with a single large channel. Before the delta toe reached the overfall, $h_{*}=0.563-0.793, \kappa=0.575-0.730$ and $G_{\text {index }}=0.578-0.659$, which were estimated the same way as for the R series runs (Eqs. 4, 9-11, Appendix 2).

Soon after the delta toe reached the shelf edge, however, the feeder alluvial system 
consisted of only a single large channel, or a valley, that was stabilized to the axial area of the delta, the outside of which showed terraced surfaces. The valley had a depth up to $10 \mathrm{~mm}$, several times as deep as the feeder streams. Simultaneously, the ABT migrated slightly basinward and then stopped for an extended period of time. The active feeder system ceased to migrate laterally over the entire alluvial surface but stayed inside the valley, and the entire delta appeared to be stationary despite the continuous supply of water and sediment from upstream (Figs. 5, 6A). In fact, both the ABT and the axial channel were not very stationary even after the delta toe reached the shelf edge but oscillated to an insignificant extent with decreasing amplitude (Fig. 7A).

Runs F2-F4 showed differences from Run F1 (Figs. 6B-D). In Run F2, which was conducted with a slightly lower $Q_{\mathrm{w}}$, the feeder alluvial river appeared to be stabilized, as was that of Run F1 after the delta toe reached the shelf edge. However, even after this state was attained, the active alluvial system abruptly made a temporary excursion away from the axial position and showed multiple simultaneous active channels. In this episodic event, the active channel notably subsequently returned to the axial position $(t=2200-2800 \mathrm{~s})$. While the active channels deviated from the axial position, the ABT moved upstream or downstream to an insignificant extent.

In Run F3, a delta was built on a shelf surface with a gentler slope than in Runs F1 and F2 but with nearly the same $Q_{\text {w }}$ and $Q_{\mathrm{s}}$ as in Run F1 (Table 1). Active channels appeared to have ceased migrating and avulsing at $t \sim 3000 \mathrm{~s}$ (Fig. 6C), although the delta toe had reached the shelf edge at $t \sim 2200 \mathrm{~s}$. Until $t \sim 3000 \mathrm{~s}$, the ABT tended to migrate upstream; thereafter, it moved slightly downstream and remained fixed in position. A characteristic of this run is that even after this point in the run, the active channel still continued to move laterally but within a relatively smaller range (mostly within $80^{\circ}<\theta<115^{\circ}$; see also Fig. 7B). Actually, this movement was oscillation rather than migration. The cyclic oscillation of the ABT was synchronized with the cyclic behaviour of the feeder channels, i.e. the ABT migrated basinward when a single major channel was being degraded in the axial part and migrated landward when multiple small channels were present and migrating (Fig. 7B).

Run F4, which was conducted with a relatively low $Q_{w}$, showed analogous behaviour to that of the axial channel in Run F3 but in a much more striking manner (Figs. 6D, 7C). Although the feeder alluvial system was stabilized to a relatively wide valley, it continued to show changes in the channel pattern, cycling through the following: (1) a single large channel in the axial position, (2) mid-bar aggradation, (3) the bifurcation of the axial channel, (4) the progressive separation of the channels in transverse directions, and (5) the abrupt recurrence 
of a new single major channel in the axial position. Before the delta toe reached the shelf edge, the feeder channels migrated over the entire delta plain (i.e. $\theta=0^{\circ}-180^{\circ}$ ). When the axial channel was undergoing bifurcation and when the subsequently bifurcated channels moved apart from each other, the ABT continued to migrate landward. On the other hand, when the bifurcated channels were converging to form a single large channel, the ABT was migrating downstream. This cyclic oscillation of the ABT synchronized with the cyclic behaviour of the feeder channels, which is similar to the one that was observed in Run F3 but in a much more distinctive manner (Fig. 7C).

In all the F series runs, distinct terraces formed along the axial channel of the delta plain, which resulted from the incision of a valley and the oscillatory behaviour of the channels that accommodated within it. Among these features, the formation of terraces at different heights in Run F4 was striking, which reflected the cyclic change in channel patterns (Fig. 8). These features appeared to have the following characteristic tendencies: (1) higher (i.e. older) terraces have higher slopes, and (2) the terraces extend downstream close to the shoreline (i.e. base level).

\section{Interpretation}

The sustained standstill of the ABT in the late stage of Run F1 (i.e. after the delta toe reached the shelf edge) suggests that the alluvial system was successfully graded $\left(R_{\mathrm{agg}} \sim 0\right)$. The formation of terraces (i.e. the incision of an axial channel) reflects the sudden transition from an aggradational regime to a graded state. While the alluvial system was aggrading, the delta plain had a relatively high alluvial slope because of the upstream sediment accumulation. At the onset of the channel incision, the river flow was concentrated to the axitial portion of the delta plain that now had a critically high alluvial slope. This was the moment of the initiation of the final process of approaching a graded state. During the interval of channel incision, the river reduced its longitudinal slope because of the concentration of the entire water discharge to the inside of the axial channel (n.b. the water and sediment supply to the ABT remained constant). This slope reduction is a direct mechanism of terracing and is related to the process of the attainment of grade. When the alluvial system is graded, Eq. 11 is no longer valid because $h *$ is no longer given by Eq. 9 but can be regarded as virtually $+\infty$ (so that $R_{\text {pro* }} \sim 0$ ). In terms of the general definition of $G_{\text {index }}$ (Eq. 4$), \chi(h *)$ is then virtually $+\infty$ (i.e. $G_{\text {index }} \sim 0$ ) because all the supplied sediment bypassed the alluvial realm. Furthermore, the axial channel is stabilized $\left(R_{\text {mig* }^{*}} \sim 0\right)$ and no longer avulses $\left(\tau_{\mathrm{A}^{*}} \sim+\infty ; f_{\mathrm{A}^{*}} \sim 0\right)$. 
In Run F2, a similar interpretation can hold as for Run F1. A temporary excursion of the main channel from the axial position was autogenic because the external conditions $\left(Q_{\mathrm{s}}, Q_{\mathrm{w}}\right.$, and base level) did not change. Notably, the channel autonomously returned to the axial position in a short time, which suggests that the alluvial river recovered grade by itself. On the other hand, the alluvial channels in Runs F3 and F4 were not strictly graded, as demonstrated by the oscillation of both the main channel and the ABT (Figs. 6C, 6D, 7). In these two runs, local erosion was evident and sediment accumulated locally even after the delta toe reached the overfall. In Run F4, a relatively low ratio of $Q_{\mathrm{w}} / Q_{\mathrm{s}}$ can account for local sediment accumulation within the valley, which caused the feeder stream to bifurcate. On the other hand, why the feeder stream in Run F3 behaved differently from the one in Run 1 is not clear despite having similar experimental conditions of $Q_{\mathrm{s}}$ and $Q_{\mathrm{w}}$. In general, the channel oscillations in these runs were limited to a relatively narrow spatial range and thus looked to be stable as a whole, particularly when considered in terms of a relatively long time scale. In this sense, the state that was attained in Runs F3 and F4 can be referred to as closely graded. The feeder alluvial channel at grade tended to be stabilized in the axial position with insignificant lateral shifting, whereas the feeder channel in an aggradational stage (i.e. before reaching the shelf edge) tended not to remain in a particularly limited zone but frequently migrated laterally and often avulsed.

The formation of terraces along the axial channel was a direct consequence of the attainment of grade. More accurately, this process represented the final stage of the river approaching a graded state. As will be discussed later, the recognition of terraces can be a key to identifying graded alluvial rivers in natural systems.

\section{Series}

\section{Experimental Method and Design}

The M series of runs was conducted with no fixed boundary but with a steady fall in base level to produce autogenic grade. The basin floor was set to have a uniform basinward inclination, similar to that in all other runs. A necessary condition for the attainment and maintenance of autogenic grade is that the basin floor has the same slope as the alluvial graded river, as noted above. To achieve this setup, preliminary experiments for both Runs M1 and M2 were conducted to measure an alluvial slope at grade for a given set of $Q_{\mathrm{s}}$ and $Q_{\mathrm{w}}$ with the use of a downstream weir (Fig. 1C). The basin slope was then adjusted to be equal to the axial alluvial slope (i.e. $\alpha \sim \phi$ ) and was zero in directions perpendicular to the alluvial slope. This method of producing a graded river was basically adopted from the experiments of 
Muto and Swenson (2006), except that these authors used a $2 \mathrm{~cm}$-wide flume.

In Run M1, the base level dropped at a constant rate of $0.00124 \mathrm{~cm} \mathrm{~s}^{-1}$ from the beginning of the run. This process was performed by using an electromagnetic flow metre that accurately pumped water out at a set discharge. The basin floor slope $\phi$ was 0.0700 , and the hinterland slope $\gamma$ was 0.216 . The floor of the flume was transversely fluted (to a small depth measured in millimetres), similar to the teeth of a saw, to decelerate the flow. The initial shoreline was located at the intersection between the hinterland basement and the basin floor. A delta was built with constant $Q_{\mathrm{w}}\left(28.3 \mathrm{~cm}^{3} \mathrm{~s}^{-1}\right)$ and constant $Q_{\mathrm{s}}\left(0.293 \mathrm{~cm}^{3} \mathrm{~s}^{-1}\right)$, and thus $Q_{\mathrm{w}} / Q_{\mathrm{s}}=96.6$. Under these conditions, the autostratigraphic length scale and time scale in a 3D spatial setting (Muto \& Steel, 1997) are given by $\Lambda_{3 \mathrm{D}}=15.4 \mathrm{~cm}$ and $\tau_{3 \mathrm{D}}=867 \mathrm{~s}$, respectively, where $\Lambda_{3 \mathrm{D}}$ and $\tau_{3 \mathrm{D}}$ are calculated as follows:

$$
\begin{aligned}
& \Lambda_{3 \mathrm{D}}=\sqrt{\frac{Q_{\mathrm{s}}}{\left|R_{\mathrm{bf}}\right|}} \\
& \tau_{3 \mathrm{D}}=\alpha \frac{\Lambda_{3 \mathrm{D}}}{\left|R_{\mathrm{bff}}\right|}
\end{aligned}
$$

where $R_{\text {blf }}$ takes a negative value in the case that base level rise is considered. The run time of Run M1 (2985 s) at this latter scale was $3.44 \tau_{3 \mathrm{D}}$.

In Run M2, $\phi=0.0594$ and $\gamma=0.331$. The basin floor was not fluted but was very Smooth, considering that the foreset height of the delta was significantly small. The initial shoreline was located at the intersection between the hinterland basement and the basin floor. With a constant $Q_{\mathrm{w}}\left(28.4 \mathrm{~cm}^{3} \mathrm{~s}^{-1}\right)$ and a constant $Q_{\mathrm{s}}\left(1.13 \mathrm{~cm}^{3} \mathrm{~s}^{-1}\right)$, a delta was built with $Q_{\mathrm{w}} / Q_{\mathrm{s}}=25.1$, which was much lower than that in Run M1. The base level was continuously lowered with $R_{\mathrm{blf}}=0.00353 \mathrm{~cm} \mathrm{~s}^{-1}$ by mechanical pumps that were connected to weirs. Under these conditions, the autostratigraphic scales are $\Lambda_{3 \mathrm{D}}=17.9 \mathrm{~cm}$ and $\tau_{3 \mathrm{D}}=301 \mathrm{~s}$. Because of the small value of $\tau_{3 D}$ and the use of a large tank, Margi 4, the alluvial system could be observed for a long time (6570 s, i.e. $\left.21.8 \tau_{3 D}\right)$.

\section{Experimental Result}

Sequential images of the formation of deltas in Runs M1 and M2 are shown in Figs. 9 and 10, respectively. In the initial stage of Run M1, the alluvial feeder system had no distinct stream channels but developed a single deltaic lobe by sheetflow (Fig. 9A). As the delta grew, sheetflow began to branch off and become localized to develop discrete 'channel-and-lobe' units (Figs. 9B-E), where the channel-and-lobe is defined as a set of channel and 
accompanying deltaic lobe at the downstream end. Those channel-and-lobe units seldom migrated in transverse directions and never avulsed but simply extended basinward in a linear trend. Reflecting this basinward extension, active shoreline segments progressively decreased in azimuth intervals as they migrated basinward (Fig. 11A). During the run, the ABT consistently migrated basinward at a decelerating rate. The net migration distance of the ABT that was measured at the end of the run was $7.5 \mathrm{~cm}\left(0.49 \Lambda_{3 \mathrm{D}}\right)$, whereas a major lobe extended basinward with a length of $111.5 \mathrm{~cm}\left(7.24 \Lambda_{3 \mathrm{D}}\right)$. The thickness of the lobe was in the range of $1.5-2.5 \mathrm{~cm}$.

The pattern that was observed in Run M2 (Fig. 10) was basically the same as that in Run M1 with respect to the basinward linear extension of an active channel-and-lobe unit, but the distance travelled was much longer (386 cm, i.e. $21.6 \Lambda_{3 \mathrm{D}}$ ) than that in Run M1. The lobe had a thickness of $0.1-0.6 \mathrm{~cm}$. In Run M2, the ABT migrated landward during an early stage with a decelerating rate and came close to stopping during the late stage. The landward migration distance of the ABT $(6.2 \mathrm{~cm})$ was only $0.35 \Lambda_{3 \mathrm{D}}$, which was negligibly small when compared to the basinward travel distance of the channel-and-lobe unit. Figure 12 shows the dimensionless trajectories of the active shoreline segments and the ABT, both of which are shown in a linear scale instead of azimuth angles. The trajectories that were obtained from Run M1 showed considerable overlap with the trajectories from the early part of Run M2.

\section{Interpretation}

The eventual standstill of the ABT during Run M2 implies that the feeder alluvial river had attained grade. In contrast, the alluvial system in Run M1, where the ABT did not stop migrating, was still in the middle of approaching a graded state, even at the end of the run (Fig. 11). The linear-scale, dimensionless shoreline trajectory diagram (Fig. 12) suggests that the alluvial system in Run M1 represented only the very early phase of the process of approaching a graded state, whereas almost the entire period of the approach to grade was captured in Run M2. Figure 12B also implies that this process requires $\sim 10 \tau_{3 \mathrm{D}}$ for the channel-and-lobe system to attain a graded state, which is characterized by the halt of the $\mathrm{ABT}$ and a constant depositional width that is nearly equal to $\Lambda_{3 \mathrm{D}}$ in terms of its order of magnitude $\left(1.7 \Lambda_{3 \mathrm{D}}\right.$ at the end of Run M1, 0.5-1.7 $\Lambda_{3 \mathrm{D}}$ for the late stage of Run M2; see Fig. 12A).

The alluvial system in Run M2 was under an aggradational regime during the early stage, as suggested from the landward migration of the ABT. This observation is contrary to Run M1, 
where the ABT migrated basinward. This striking difference perhaps arose from the significant differences in magnitude of $Q_{\mathrm{w}} / Q_{\mathrm{s}}$. Because of the lower $Q_{\mathrm{w}} / Q_{\mathrm{s}}$, the upstream part of the delta plain near the ABT was possibly unsaturated with water.

\section{ATTAINMENT OF ALLUVIAL GRADE}

The results of the present 3D experiments clarify that the alluvial topset river of a delta can attain grade (or close to grade) in a setting where the river streams are free from confinement in the transverse direction. Attaining this $3 \mathrm{D}$ grade is possible by at least two different mechanisms: (1) the equilibrium response of a delta to a stationary base level in a downstream-fixed boundary setting (forced grade in the F series), and (2) the equilibrium response of a delta to constant base-level fall in a moving boundary setting where the basin floor has the same slope as the alluvial topset (autogenic grade in the M series). In stark contrast, a feeder alluvial river that can freely prograde (unlike the F series) never becomes graded in a moving-boundary system with a stationary base level (the R series). The results of these 3D experiments are consistent with existing 2D models (Muto \& Swenson, 2005a, 2006) and thus are critical to the conventional notion that alluvial grade in a prograding deltaic system is attained with a stationary base level (e.g. Posamentier et al., 1988; Galloway, 1989; Shanley \& McCabe, 1994).

Under downstream-fixed conditions, alluvial grade can be attained with a stationary base level, as shown by the F series runs. At the very moment of the attainment of grade, however, valley incision inevitably occurs, i.e. a significant erosion of existing delta deposits (Fig. 5; see also Kim et al., 2013; Bijkerk et al., 2016). The resulting graded streams run through the valley, outside of which are paired stream terraces and an abandoned delta plain surface. This view of alluvial grade is significantly different from the one that has been incorporated into conventional sequence stratigraphy and raises doubts with respect to the conceptual validity and physical significance of 'subaerial accommodation,' which is defined as the space between the existing fluvial or coastal plain and the position in space of the graded profile (Posamentier et al., 1988; Posamentier \& Allen, 1999). Subaerial accommodation clearly cannot be defined with rising or stationary base level, i.e. the alluvial river has no vertical aggradation limit if only sediment is available (see also Muto \& Swenson, 2005b). Subaerial accommodation could be defined by sea level fall but only under a particular geomorphic condition $(\alpha<\phi)$ (Fig. 12; see also Petter \& Muto, 2008), although whether such subaerial accommodation makes sense in sequence stratigraphy is uncertain. The experimental results 
imply that subaerial accommodation is a conceptual flaw (see also Muto \& Steel, 2000, 2014).

\section{INHERENT SPATIAL STABILITY OF THE GRADED SYSTEM}

Another important finding in the present study is the stabilization that is inherent to a graded alluvial channel (or channel-and-lobe unit), as shown by the experimental runs in the $\mathrm{F}$ and $\mathrm{M}$ series and the geometrical model that incorporates grade index. The autocyclic transverse shifting of active alluvial channels appears to be suppressed in the graded system regardless of whether the downstream boundary is fixed. A primary mechanism of channel stabilization is understood in terms of analysing what happens in an aggradational alluvial system. In an aggrading alluvial system (the R series), the global topography continuously changes in association with channel migration and avulsion, i.e. local erosion and deposition under the regime of progressive burial. Local sediment accumulation along channels, which is accompanied by the modification of local transverse gradients, functions to force the active channel to change its flow path, which then gives rise to new local events of erosion and simultaneous or subsequent deposition (Van Dijk et al., 2009). With this autocyclic feedback process, active channels consistently change their positions with occasional avulsions such that the alluvial system can produce a uniform depositional surface as a whole after a relatively long lapse of time. This process is also called 'compensational stacking' (Straub et al., 2009). Once a feeder channel has attained grade (the F series), on the other hand, global aggradation no longer occurs, although local accumulation and erosion are still possible as implied from Run F4. Even in this case, however, the autocyclic behaviour of feeder channels does not prevail over the entire alluvial system but is suppressed to a limited extent along the axial part of the entire system.

In the case of the F series, a rationale for the stabilization of graded channels is provided in terms of the grade index, i.e., the effects of the basin water depth. This notion is consistent with the experimental results of another series of runs by Muto et al. (2011), who built deltas on a differential basement to clarify the control of the local basin water depth on the growth of the deltaic body. In their experiments, the differential basement was created by placing a platform on the horizontal bottom surface, with a water depth of $7.2 \mathrm{~cm}$ on the platform and $0.7 \mathrm{~cm}$ elsewhere. Because the maximum thickness of the final alluvial deposit was no more than $4 \mathrm{~cm}$, the differential water depth must have exerted a marked influence on delta progradation. Nevertheless, the resulting shoreline always retained a quasi-isotropic, arcuate configuration, which indicates that a channel selectively stays where it empties into deeper 
water for a longer period of time and migrates more slowly than where it empties into shallower water (see also Bijkerk et al., 2016). Thus, the basin water depth does affect the dynamics and autocyclic behaviour of distributary channels in the delta plain. If the basin water in front of the delta is extremely deep (such that the delta cannot prograde, as in the $\mathrm{F}$ series), the feeder channels will be stabilized in disassociation with autocyclic lateral shifting and avulsion (i.e. $R_{\mathrm{pro}^{*}} \sim 0, R_{\mathrm{agg} *} \sim 0, R_{\mathrm{mig}^{*}} \sim 0, f_{\mathrm{A}^{*}} \sim 0, \tau_{\mathrm{s}^{*}}{ }^{-1} \sim 0$, and $G_{\text {index }} \sim 0$ ). With respect to this multi-functional effect of basin depth, Bijkerk et al. (2016) address closely related topics and conclude from a different experimental analysis that a delta prograding into deeper water gets closer to a graded state and is more susceptible to form an incised valley on the topset than a delta prograding into more shallow water. Notably, this latter notion is consistent with the results of F series runs where alluvial channels feeding a delta prograding into an extremely deep water eventually cut an axial valley on the delta plain and then became graded.

On the other hand, the effect of the basin water depth does not account for the attainment of autogenic grade in the $\mathrm{M}$ series runs, where the basin water depth right in front of the delta depends on $R_{\mathrm{blf}} q_{\mathrm{s}}$, and the delta's geometry (Eq. 3). Thus, if we are to extend the grade index model to the alluvial process approaching autogenic grade, the general equation (Eq. 4) would require a significant modification. In the M series (especially Run M2), alluvial grade was attained because of delta progradation $\left(R_{\text {pro }}=\right.$ const $\left.>0\right)$ and constant base-level fall $\left(R_{\mathrm{blf}}=\right.$ const $>0$ ), whereas this status was attained under the serious control of basin water depth in the F series. Despite this fundamental difference, however, the graded alluvial channels that were observed in the M series show basically the same behaviour as in the F series in the respect that they did not migrate significantly in transverse directions and thus behaved in a non-compensational manner, which is described as follows:

$$
R_{\text {agg }} \sim 0 \Leftrightarrow R_{\text {mig }} \sim 0 \quad \text { (but } R_{\text {pro }}>0 \text { ) }
$$

Because of the moving boundary setting, sediment accreted on the delta's foreset slope, which allowed the active channel(s) to extend basinward, whereby a far-basinward protruding lobe formed, which left the ABT far behind landward.

\section{SEARCH FOR GRADED ALLUVIAL RIVERS IN NATURAL SYSTEMS}

The present experimental study implies that an alluvial river that feeds a delta can be graded in the following two scenarios: (1) with stationary base level, the delta develops a bypass system and transports all sediment into deep water $\left(h_{*}>>1\right)$ and cannot prograde (i.e. forced grade); and (2) with constant base-level fall, the delta progrades above a preformed alluvial 
surface that extends basinward during a preceding base-level fall and then drowns during a subsequent base level rise (i.e. autogenic grade). Following these implications, natural environments in which graded alluvial rivers are likely to be found are predicted.

\section{Modern Fan Deltas in Front of Deep Water}

An alluvial river at forced grade would most likely be found in modern fan deltas that have developed in front of deep water $(h *>>1)$ such that the delta cannot prograde basinward $\left(R_{\text {pro }} \sim 0\right)$. A criterion to identify graded alluvial systems, as suggested from the F series runs, is the presence of river terraces along an axial channel/valley that was incised into the delta plain of the previous stage by the process of approaching grade.

Incised stream channels and their adjacent terraces have usually been attributed to the graded versus non-graded states of the rivers (Ritter, 1967; Bull, 1979, 1991; van Heijst and Postma, 2001) and ultimately to changes in rates or types of external dynamic forcing, such as tectonic uplift, the eustatic fluctuation of sea level, or climate change, which affects precipitation and detritus productivity in the watershed (Bull, 1991; Veldkamp, 1992). In addition to these perturbations in the environment, which produce instability in the fluvial system (Merritts et al., 1994; Hancock \& Anderson, 2002), river deltas show repeated incision and multiple terrace formations with constant base-level fall (Muto \& Steel, 2004). Those autogenic terrace surfaces basically have the same slope as the feeder alluvial river that runs between the terraces. On the other hand, the autogenic terraces that are produced with a stationary base level in the F series runs had higher slopes than the feeder channel; thus, a higher (older) terrace has a higher slope, and a lower (younger) terrace has a lower slope (Fig. 8). This relationship can be a criterion to identify graded alluvial systems that were produced under downstream-fixed boundary settings.

Fan deltas that appear to illustrate the latter type of autogenic terraces are found on the Japan Sea coast of central Japan, which is located to the south of Toyama Bay, where the Toyama Deep-Sea Canyon (TDSC) extends close to the coastline (Nakajima, 2006; Fig. 13). The southern landward margin of Toyama Bay is steep (15 $)$, high in relief (up to $1000 \mathrm{~m}$ ) and fringed by a very narrow (0-4 km wide) shelf. Several small tributary canyons in the TDSC are deeply incised in the bay's marginal slope, with head segments extending to the mouths of the rivers that have fed sediment to the fan deltas. Immediately landward of the fan deltas are the Northern Japan Alps, a range that includes the highest mountains in Japan, with peaks rising $3000 \mathrm{~m}$ above sea level. 
Figure 14 shows the longitudinal profiles of terraces along the axial channels of the Kurobegawa, the Katakaigawa, the Hayatsukigawa and the Joganjigawa (gawa = river in Japanese). Among them, the Joganjigawa fan is presently separated from the coastline, but a geological section of the Joganjigawa fan to the Toyama Bay coast (Fujii et al., 2011) shows that the river, or an ancestral one, was previously building a fan delta at the brink of the TDSC. The longitudinal profile of each river has a nearly uniform downstream slope and thus is approximated with a straight line, with an exception for the lowermost reaches of the Joganjigawa. The mean alluvial slopes $(\alpha)$ vary significantly, ranging between 0.0090 and 0.0197 for the present river beds and between 0.011 and 0.0204 for the youngest terraces (< $10 \mathrm{kaBP})$. The ages of the terraces also vary; for example, the oldest terrace of the Joganjigawa formed at 45-55 kaBP, whereas no terrace of this age range is present in the Kurobegawa, where the oldest terrace formed at 20-30 kaBP. Nevertheless, in each of the rivers (1) the present-age profile has a gentler slope than the terraces and (2) higher (i.e. older) terraces have steeper slopes (Fig. 14).

Neotectonic movements in the Toyama Bay region could account for the tendency for a progressive decrease in terrace slopes. In fact, this region has subsided as much as $10 \mathrm{~cm}$ for ca. 100 years from 1883-1913 to 1986-2000 relative to the Northern Japan Alps region, which has also subsided but by a smaller amount (Geographical Survey Institute, 2002). However, whether this subsidence trend has persisted for a much longer period (e.g. $10^{5}$ years) and whether the coastal region has been undergoing a tectonic tilt basinward are uncertain. If the progressive decrease in terrace slopes were completely because of the cumulative tectonic tilting of the region, the rate of tilting would have been significantly different between rivers, e.g. $0.0092^{\circ}-0.0138^{\circ} \mathrm{ka}^{-1}$ in the Joganjigawa, but $0.0160^{\circ}-0.0235^{\circ}$ $\mathrm{ka}^{-1}$ in the Kurobegawa. An alternative mechanism is the alluvial process of approaching grade, which is shown by a progressive decrease in $G_{\text {index. }}$ The values of $G_{\text {index }}$ can be calculated with Eq. 6 on the assumption that (1) tectonic tilting is not significant and (2) $h$ $\sim 1000 \mathrm{~m}$ and $\beta \sim 0.27\left(15^{\circ}\right)$ (ref. Nakajima, 2006). In the case of the Kurobegawa fan delta ( $x$ $=13.3 \mathrm{~km}$ ), for example, $G_{\text {index }}$ decreased from 0.003 at 20-30 kaBP to 0.0005 at present, which implies that the Kurobegawa has been getting closer to grade during the past 20-30 ka. A similar trend in $G_{\text {index }}$ is shown for the other three rivers (Fig. 14).

The ages of the terraces in the Toyama Bay coastal region are up to over $100 \mathrm{kaBP}$ (Fig. 14), and the eustatic sea level has since changed, with an amplitude of over $100 \mathrm{~m}$. However, even with this magnitude of eustatic fluctuation, no significant changes were apparent in the 
topographic setting in which the deltaic systems were located in front of the deep water, at least during the past $10^{5}$ years. Provided a set of assumptions, the avulsion time scale for the river systems can be calculated with Eqs. A15 and A17:

$$
\begin{aligned}
& \tau_{\mathrm{A}_{h-0}}=\frac{\lambda h_{\mathrm{c}} x^{2}}{2 q_{\mathrm{sy}} A} \\
& \tau_{\mathrm{A}}=\tau_{\mathrm{A}_{h-1}} G_{\text {index }}
\end{aligned}
$$

where $h_{\mathrm{c}}$ is the average channel depth, $q_{\mathrm{sy}}$ is the sediment yield intensity (the rate of sediment yield per unit area in the hinterland) and $A$ is the drainage area; thus $Q_{\mathrm{s}}=q_{\mathrm{sy}} A$. In the case of the Kurobegawa at 20-30 kaBP, $\lambda \sim \pi / 4, q_{\mathrm{sy}}=1.929 \times 10^{3} \mathrm{~m}^{3} \mathrm{~km}^{-2}$ year $^{-1}$ and $A=667 \mathrm{~km}^{2}$ (Kobayashi \& Tanaka, 2012). Historical recorded flood water depths were around $3 \mathrm{~m}$ (Ministry of Land, Infrastructure, Transport and Tourism, 2006), for which we assume that $h_{\mathrm{c}}$ $\sim 3 \mathrm{~m}$. With these numerical values, $\tau_{\mathrm{A}} \sim 5 \times 10^{4}$ years for the present value of $G_{\text {index }}$ (Table 2 ). If the river system were to adjust itself to approach grade at times of channel avulsion, it would require at least $5 \times 10^{4}$ years for the river to approach or attain grade.

The above discussion does not claim that the alluvial process of approaching grade was the primary mechanism that was responsible for the formation of the terraces, but suggests a possible intrinsic mechanism that was partly consistent with the observations. As mentioned, the base level (i.e. sea level) was not stationary during the terrace formations. Perhaps because of this phenomenon, the terrace intersections lie some distance inland, not at the present shoreline (Fig. 14). In addition, no clear evidence supports that $Q_{\mathrm{s}}$ and $Q_{\mathrm{w}} \operatorname{did}$ not change significantly during the past $10^{5}$ years. Our interpretation at the present stage is that the alluvial process of approaching grade was a possible mechanism that affected the terrace formations.

\section{Fossil Deltas in Outer to Marginal Shelves}

An attempt to seek out autogenically graded alluvial rivers in natural systems, whether modern or ancient, is in progress, although no clear example has yet been identified. To attain autogenic grade under moving boundary conditions, (1) the sea level (i.e. base level) must fall at a constant rate and (2) the basin slope $\phi$ must coincide with the alluvial slope $\alpha$. This geometrical condition can be realized in the outer to marginal areas of the deltaic shelf, which were originally alluvial plains but were then submerged during subsequent stages of sea-level rise, as explained by the extended autoretreat model (Tomer et al., 2011). 
Whenever the sea level rises, a river that empties into a sea has a critical alluvial length $\left(L_{\text {crt }}\right)$ over which the river cannot maintain deltaic sedimentation. $L_{\text {crt }}$ in $2 \mathrm{D}$ systems is determined by

$$
L_{\mathrm{crt}}=\Lambda_{2 \mathrm{D}}\left(\frac{\gamma \sqrt{1+\alpha^{2}}}{\gamma-\alpha}\right) \sim \Lambda_{2 \mathrm{D}}(\text { if } \alpha<<\gamma) .
$$

When no pre-existing deposits are on the shelf surface (i.e. alluvial length $L=0<<L_{\text {crt }}$ ) at the onset of sea level rise, regression occurs during the early stage of sea level rise, which is then followed by deltaic transgression and eventually by non-deltaic transgression. This critical event, reflecting an autogenic non-equilibrium response to steady sea level rise, is referred to as 'autobreak' for $\gamma<\beta$ (Muto, 2001) or 'autodrowning' for $\gamma>\beta$ (Tomer et al., 2011). The autobreak event occurs at the moment when $L$ becomes equal to $L_{\mathrm{crt}}$. If the alluvial river has extended seaward over a significantly long distance during sea level standstill (or lowering) prior to the onset of sea level rise, the depositional system undergoes rapid nondeltaic transgression as soon as the sea level starts to rise, whereby a critical event that looks like autobreak occurs, although this event is clearly allogenic because it arises from the transition from sea level stillstand to rise. Thereafter, the sediment that is supplied through the ABT is entirely consumed for the feeder alluvial river to aggrade and is no longer able to accumulate beyond the shoreline (i.e. $G_{\text {index }} \sim 1$ ). Then, the shoreline, which is now non-deltaic, rapidly recedes landward and leaves a concave-upward, sediment-starved surface, the downstream part of which can have the same slope as $\alpha$.

During the subsequent cycle of sea level fall, a new delta can have a chance to prograde on the previously starved submarine floor that has a slope of $\alpha$, which favours the feeder alluvial river to attain grade, particularly if the sea level falls at a constant rate. The stratigraphic signal of ancient graded rivers, if any, might be found in the strata of the outer to marginal part of broad shelves that accumulate during sea level fall. Such deltas would lack topset strata and significant fluvial erosional features and would also be characterized by the development of channel-and-lobe units that have extended basinward.. Such lobes would have a particular transverse width ( $W_{\text {lobe, }}$ in total) that is nearly equal to or in the same order of magnitude as $\Lambda_{3 \mathrm{D}}$, if the results of the $\mathrm{M}$ series runs are directly applicable to natural systems (Fig. 12). The following approximate relationships would then be suggested:

$$
\begin{aligned}
Q_{\mathrm{s}} & =\left|R_{\mathrm{blf}}\right|\left(\Lambda_{3 \mathrm{D}}\right)^{2}=q_{\mathrm{s}} W_{\text {lobe }} \sim q_{\mathrm{s}} \Lambda_{3 \mathrm{D}} \\
q_{\mathrm{s}} & \sim R_{\mathrm{bff}} \mid \Lambda_{3 \mathrm{D}}
\end{aligned}
$$




$$
\Lambda_{3 \mathrm{D}} \sim \Lambda_{\mathrm{2D}}
$$

Combined with Eq. 2, the set thickness of the delta lobes that are fed by autogenically graded alluvial channels would be given by

$$
h_{\mathrm{set}} \sim \frac{\Lambda_{3 \mathrm{D}}}{\sqrt{1+\alpha^{-2}}}
$$

With the experimental data from the M series, Eq. 21 shows that $h_{\text {set }} \sim 1 \mathrm{~cm}$ for both Runs M1 and M2. This estimated value is not significantly different from the measured values of $h_{\text {set }}$ in Run M1 (1.5-2.5 cm) and Run M2 $(0.1-0.6 \mathrm{~cm})$, if compared in terms of the order of magnitude.

For a hypothetical case that $R_{\mathrm{blf}}=5 \mathrm{~mm}$ year ${ }^{-1}, Q_{\mathrm{s}}=10^{6} \mathrm{~m}^{3}$ year-1 (roughly equivalent to the Kurobegawa, the Columbia, and the Lena Rivers: ref. Milliman \& Syvitski, 1992) and $\alpha=$ $\phi=0.001$, the feeder alluvial system has scales of $\Lambda_{3 \mathrm{D}} \sim 14 \mathrm{~km}\left(\sim W_{\text {lobe }}\right)$ and $\tau_{3 \mathrm{D}} \sim 3 \times 10^{3}$ years and this is expected to attain grade, or a state close to grade, after $3 \times 10^{4}$ years $\left(\sim 10 \tau_{3 \mathrm{D}}\right)$, during which the delta progrades for a distance of $140 \mathrm{~km}\left(\sim 10 \Lambda_{3 \mathrm{D}}\right)$. For this scenario to be realized, the shelf width is required to be $140 \mathrm{~km}$ or more. After the alluvial channel has become graded, the set thickness of the delta lobe is $14 \mathrm{~m}$ (Eq. 21). Such a deltaic lobe with these 'realistic' dimensions looks to be quite possible in natural shelf systems. Thus, a thorough investigation of outer to marginal shelves is expected to result in the identification of ancient graded rivers.

The modern Volga delta, which progrades into the northern Caspian Sea, appears to provide a natural example that shows an early stage of the attainment of autogenic grade. The Caspian Sea is an inland closed basin but has extremely shallow shelf-like topography in its northern part. The present Volga delta has a length of $130 \mathrm{~km}$ and a coastline width of $200 \mathrm{~km}$ (Mamaev, 2002). From 1930 to 1977, a sea level fall of $2.7 \mathrm{~m}\left(R_{\mathrm{blf}} \sim 5.7 \mathrm{~cm}\right.$ year $\left.{ }^{-1}\right)$ occurred in association with the rapid progradation of sandy levees (along hundreds of distributary channels along the delta front) for several tens of kilometres $\left(R_{\text {pro }} \sim 2.5 \mathrm{~km}\right.$ year ${ }^{-1}$ for the interval 1931-1955) but without the significant downcutting of channel mouths (Overeem et al., 2003). In addition to the sea level fall, the rapid progradation was partly related to very gentle onshore and offshore slopes $\left(\alpha \sim \phi \sim 5 \times 10^{-5}\right)$ and sufficient sediment supply $\left(Q_{\mathrm{s}}=\right.$ $9.5 \times 10^{6} \mathrm{~m}^{3}$ year $\left.^{-1}\right)$. With these field data, the autostratigraphic length and time scales that are estimated with Eqs. 12 and 13 for this period are $13 \mathrm{~km}\left(\Lambda_{3 \mathrm{D}}\right)$ and 11 years $\left(\tau_{3 \mathrm{D}}\right)$, respectively. The measured thickness of progradational sand bodies is less than $1.5 \mathrm{~m}$ (Overeem et al., 2003), which appears to be close to an estimated value of $h_{\text {set }}(\sim 0.7 \mathrm{~m}$ : Eq. 21$)$ on the 
assumption that the feeder channels were graded. Because (1) the period for the sea level fall (47 years) is less than a half of $10 \tau_{3 \mathrm{D}}$ and (2) the delta's width $(200 \mathrm{~km})$ is much larger than $\Lambda_{3 \mathrm{D}}$, the delta progradation appears to have terminated in the middle of approaching grade.

\section{CONCLUSIONS}

1. The present tank experiments clarify that an alluvial river that feeds a delta can become graded in a 3D setting where alluvial activities are not confined by unerodible basement topography in transverse directions. Three-dimensional alluvial grade can be attained through at least two different methods: (1) 'forced grade,' which is attained by an equilibrium response to a stationary base level in a downstream-fixed boundary setting; and (2) 'autogenic grade,' which is attained by an equilibrium response to a constant base-level fall in a moving-boundary setting.

2. The autocyclic lateral shifting and avulsion of river channels tends to be intensely suppressed in a graded alluvial system, whether the state of the attained grade is forced or autogenic. A graded alluvial channel can be stabilized to a particular location of the delta plain (e.g. axial part) and seldom moves from that position. The feeder alluvial river at forced grade is located within a valley that incises the delta plain, whereby the outside surface of the channel becomes paired stream terraces. Under a moving-boundary setting, on the other hand, the feeder river at autogenic grade simply extends basinward as a linearly elongated channel-and-lobe system without valley incision and lateral shifting. A delta that is fed by this type of graded river can have a long and narrow lobe extending basinward over a large distance.

3. The basin water depth in front of a delta affects the dynamics and time scales of distributary channels on the delta plain. As the basin water depth increases, channel migration slows and avulsion occurs less frequently. If the basin water is extremely deep, neither migration nor aggradation occurs. Forced grade attained in a downstream-fixed setting, which represents the latter case. This synthetic view, which is described with the grade index, encompasses (1) delta progradation, (2) alluvial aggradation and grade, (3) channel shifting and stabilization, and (4) the time scales of channel behaviour, which account for what happened in the runs of the F series.

4. Natural environments that favour the attainment of alluvial grade include (1) modern fan deltas that develop in front of very deep water (forced grade) and (2) ancient deltas that prograde over outer to marginal shelves with falling sea level (autogenic grade). Searches for recent, subrecent or ancient graded rivers will most likely be successful in these places. 
A possible natural example of forced grade is provided by the Late Pleistocene alluvial rivers that empty into the deep water of Toyama Bay in central Japan. The modern Volga delta, particularly during 1930-1977, approached autogenic grade, but the period of sea level fall was not sufficient to allow the attainment of a fully graded state.

\section{ACKNOWLEDGMENTS}

This work was financially supported in part by a Japanese Grant-in-Aid for Scientific Research (B2034140, C25409489) to TM. Critical comments that were provided by Sedimentology reviewers (Joris Eggenhuisen, John Shaw, and AE Vern Manville) were very constructive and helpful in the revision of an early version of the manuscript.

\section{NOMENCLATURE}

\begin{tabular}{|c|c|c|}
\hline Symbol & Meaning & $\begin{array}{l}\text { Dimensions } \square(\mathrm{L} \text {, } \\
\text { length; T, time; } 1 \text {, } \\
\text { dimensionless) }\end{array}$ \\
\hline$A$ & Drainage area & $\mathrm{L}^{2}$ \\
\hline$B$ & Average width of active channels & $\mathrm{L}$ \\
\hline$f_{\mathrm{A}}$ & Avulsion frequency & $\mathrm{T}^{-1}$ \\
\hline$f_{\mathrm{A} h \sim 0}$ & Avulsion frequency when $h \sim 0$ & $\mathrm{~T}^{-1}$ \\
\hline$f_{\mathrm{A}^{*}}$ & Avulsion frequency normalized with $f_{\mathrm{A} h \sim 0}$ & 1 \\
\hline$G_{\text {index }}$ & Grade index & 1 \\
\hline$h$ & Basin water depth in front of a delta & $\mathrm{L}$ \\
\hline$h *$ & Dimensionless basin water depth in front of a delta & 1 \\
\hline$h_{\mathrm{C}}$ & Channel depth & $\mathrm{L}$ \\
\hline$L$ & Alluvial length of a river & $\mathrm{L}$ \\
\hline$L_{\text {crt }}$ & Critical alluvial length of a river & $\mathrm{L}$ \\
\hline$N$ & Number of channels & 1 \\
\hline$R_{\text {agg }}$ & Rate of delta-plain aggradation & $\mathrm{LT}^{-1}$ \\
\hline$R_{\text {aggh } \sim 0}$ & Rate of delta-plain aggradation when $h \sim 0$ & $\mathrm{LT}^{-1}$ \\
\hline$R_{\text {agg* }}$ & Dimensionless rate of delta-plain aggradation & 1 \\
\hline$R_{\mathrm{mig}}$ & Rate of active shoreline migration & $\mathrm{LT}^{-1}$ \\
\hline$R_{\text {migh } \sim 0}$ & Rate of active shoreline migration when $h \sim 0$ & $\mathrm{LT}^{-1}$ \\
\hline$R_{\text {mig* }}$ & Dimensionless rate of active shoreline migration & 1 \\
\hline$R_{\text {pro }}$ & Rate of delta progradation & $\mathrm{LT}^{-1}$ \\
\hline$R_{\text {proh } \sim 0}$ & Rate of delta progradation when $h \sim 0$ & $\mathrm{LT}^{-1}$ \\
\hline$R_{\text {pro* }}$ & Dimensionless rate of delta progradation & 1 \\
\hline$R_{\mathrm{blf}}$ & Rate of base-level fall ( $R_{\mathrm{blf}}<0$ for base-level rise) & $\mathrm{LT}^{-1}$ \\
\hline$Q_{\mathrm{s}}$ & Upstream sediment discharge & $\mathrm{L}^{3} \mathrm{~T}^{-1}$ \\
\hline$q_{\mathrm{s}}$ & Upstream sediment discharge per unit width & $\mathrm{L}^{2} \mathrm{~T}^{-1}$ \\
\hline$q_{\text {sy }}$ & Sediment yield intensity & $\mathrm{LT}^{-1}$ \\
\hline$Q_{\mathrm{w}}$ & Upstream water discharge & $\mathrm{L}^{3} \mathrm{~T}^{-1}$ \\
\hline$S(\eta)$ & $\begin{array}{l}\text { Horizontal section area of the delta's subaqueous } \\
\text { deposit at depth } \eta\end{array}$ & $\mathrm{L}^{2}$ \\
\hline
\end{tabular}


$t$

$V_{\mathrm{s}}$

$V_{\text {subaerial }}$

$V_{\text {subaqueous }}$

$W_{\text {lobe }}$

$x$

$x_{\eta}$

y

$\alpha$

$\alpha *$

$\beta$

$\chi(h *)$

$\gamma$

$\phi$

$\eta$

$\kappa$

$\Lambda_{2 \mathrm{D}}$

$\Lambda_{3 \mathrm{D}}$

$\lambda$

$\theta$

$\theta_{\max }$

$\theta_{\text {min }}$

$\sigma_{\eta}$

$\tau_{2 \mathrm{D}}$

$\tau_{3 \mathrm{D}}$

$\tau_{\mathrm{A}}$

$\tau_{\mathrm{A} h \sim 0}$

$\tau_{\mathrm{A}^{*}}$

$\tau_{\mathrm{s}}$

$\tau_{\mathrm{sh} \sim 0}$

$\tau_{\mathrm{s}^{*}}$

$\tau_{\mathrm{r}}$

$\tau_{\mathrm{rh} \sim 0}$

$\tau_{\text {r* }}$

$\Omega$
Time elapsed

Rate of channel migration

Sediment volume of the subaerial part of the delta

Sediment volume of the subaqueous part of the delta

Total transverse width of active deltaic lobes

Deltaplain radius, or basinward distance

Radius of the sector representing the horizontal cross section of the subaqueous part of the delta, at depth $\eta$

Distance transverse to delta progradation

Alluvial slope in tangent

$(\alpha / \beta)$ Alluvial slope normalized with foreset slope

Foreset slope in tangent

Measure of sediment allocation in the delta's subaqueous part relative to the subaerial part

Hinterland slope in tangent

Basin floor slope in tangent

Water depth of a foreset surface

Positive number to denote the ratio of sediment

allocation of the subaqueous part to the subaerial part

Autostratigraphic length scale in two dimensions

Autostratigraphic length scale in three dimensions

Central angle of the deltaplain

$\mathrm{LT}^{-1}$

$\mathrm{L}^{3}$

$\mathrm{L}^{3}$

$\mathrm{L}$

$\mathrm{L}$

$\mathrm{L}$

$\mathrm{L}$

1

1

1

1

1

1

$\mathrm{L}$

1

$\mathrm{L}$

$\mathrm{L}$

1 (radian)

1 (degree) segment

Maximum value of $\theta$ at a given time

1 (degree)

1 (degree)

1 (radian)

Half of central angle of the sector representing the

horizontal cross section of the subaqueous part of the delta, at depth $\eta$

Autostratigraphic time scale in two dimensions $\quad \mathrm{T}$

Autostratigraphic time scale in three dimensions $\quad \mathrm{T}$

Time scale of channel avulsion $\quad T$

Time scale of channel avulsion when $h \sim 0 \quad \mathrm{~T}$

Dimensionless time scale of channel avulsion 1

Time scale of channel shifting $T$

Time scale of channel shifting when $h \sim 0 \quad \mathrm{~T}$

Dimensionless time scale of channel shifting 1

Recurrence period of channels $T$

Recurrence period of channels when $h \sim 0 \quad \mathrm{~T}$

Dimensionless recurrence period of channels 1

Positive coefficient to denote the linear relationship 1

between $R_{\text {mig }}$ and $R_{\text {pro }}$ 


\section{REFERENCE}

Bijkerk, J.F., Eggenhuisen, J.T., Kane, I.A., Meijer, N., Waters, C.N., Wignall, P.B. and McCaffrey, W.D. (2016) Fluvio-marine sediment partitioning as a function of basin water depth. J. Sed. Res., 86, in press. doi: http://dx.doi.org/10.2110/jsr.2016.9

Bull, W.B. (1979) Threshold of critical power in streams. Geol. Soc. Am. Bull., 90, 453-464.

Bull, W.B. (1991) Geomorphic responses to climatic change. Oxford University Press, New York, 326 pp.

Cantelli, A. and Muto, T. (2014) Multiple knickpoints in an alluvial river generated by a single instantaneous drop in base level: experimental investigation. Earth Surf. Dynam., 2, 271-278. doi:10.5194/esurf-2-271-2014.

Catuneanu, O. (2006) Principles of Sequence Stratigraphy. Elsevier, Amsterdam, 375 p.

Davis, W.M. (1902) Base-level, grade, and peneplain. J. Geol., 10, 77-111.

Fujii, S., Nakamura, T., Sakatani, Y., Takahashi, H., Kudo, H. and Yamano, S. (2011) Some Data about Formation and Disaster of the Jyoganji River Alluvial Fan, Hokuriku Region, Central Japan. Bulletin of the Tateyama Caldera Sabo Museum, 12, 1-10 (in Japanese).

Galloway, W.E. (1989) Genetic stratigraphic sequences in basin analysis-part I: architectures and genesis of flooding-surface bounded depositional units. AAPG Bull., 73, 125-142.

Geographical Survey Institute (2002) Vertical displacement of Japan derived from precise leveling. Report of the Coordinating Committee for Earthquake Prediction, Japan, 67, 555 (in Japanese).

Gilbert, G.K. (1877) Report on the geology of the Henry Mountains. U.S. Geogr. Geol. Surv. Rocky Mtn. Region, Washington D.C., 160 pp.

Green, J.F.N. (1936) The terraces of southernmost England. Q. J. Geol. Soc. London, 92, LVIII-LXXXVIII (Presidential address).

Hancock, G.S. and Anderson, R. (2002) Numerical modeling of fluvial strath-terrace formation in response to oscillating climate. Geol. Soc. Am. Bull., 114, 1131-1142.

Holbrook, J., Scott, R.W. and Oboh-Ikuebobe, F.E. (2006) Base-level buffers and buttresses: A model for upstream versus downstream control on fluvial geometry and architecture within sequences. J. Sed. Res., 76, 162-174.

Jerolmack, D.J. and Mohrig, D. (2007) Conditions for branching in depositional rivers. Geology, 35, 463-466.

Johnson, D.D. and Beaumont, C. (1995) Preliminary results from a planform kinematic model of orogen evolution, surface processes and the development of clastic foreland basin 
stratigraphy. In: Stratigraphic Evolution of Foreland Basins (Eds. S.L. Dorobek and C.M. Ross), SEPM, Spec. Publ., 52, 3-24.

Kesseli, J.E. (1941) The concept of the graded river. J. Geol., 49, 561-588.

Kim, Y., Kim, W., Cheong, D., Muto, T. and Pyles, D.R. (2013) Piping coarse-grained sediment to a deep water fan through a shelf-edge delta bypass channel: Tank experiments. J. Geophys. Res., 118, doi:10.1002/2013JF002813.

Kim, W. and Jerolmack, D.J. (2008) The pulse of calm fan deltas. J. Geol., 116, 315-330.

Kim, W., Dai, A., Muto, T. and Parker, G. (2009) Delta progradation driven by an advancing sediment source: Coupled theory and experiment describing the evolution of elongated deltas. Water. Resour. Res., 45, W06428, doi:10.1029/2008WR007382, 2009.

Kobayashi, Y. and Tanaka, Y. (2012) Study on relative influence of dams on downstream sediment transport systems. Apr.2011 Mar.2012 Report of Water Resources Environment Research Institute, 25-33 (in Japanese).

Leeder, M.R. and Stewart, M.D. (1996) Fluvial incision and sequence stratigraphy: Alluvial responses to relative sea-level fall and their detection in the geologic record. In: Sequence Stratigraphy in British Geology (Eds. S.P. Hesselbo and D.N. Parkinson), Geol. Soc. London Spec. Publ., 103, 25-39.

Leopold, L.B. and Bull, W.B. (1979) Base level, aggradation, and grade. Proc. Am. Phil. Soc. 123, 168-202.

Mackin, J.H. (1948) Concept of the graded river. Geol. Soc. Am. Bull., 59, 463-512.

Mamaev, V. (2002) The Caspian Sea-enclosed and with many endemic species. European Environmental Agency. Europe’s biodiversity-biogeographical regions and seas. http://www.eea.europa.eu/publications/report_2002_0524_154909/page172. html

Matsuura, T., Yoshioka, T. and Furusawa, A. (2007) Late Quaternary activity of the Uozu fault zone inferred from fluvial terrace surfaces in the eastern part of Toyama Prefecture. Quaternary Res. (Daiyonki-Kenkyu), 46, 19-36 (In Japanese with English abstract).

Merritts, D.J., Vincent, K.R. and Wohl, E.E. (1994) Long river profiles, tectonism, and eustasy: A guide to interpreting fluvial terraces. J. Geophys. Res., 99, 14,031-14,050.

Milliman, J.D. and Syvitski, J.P.M. (1992) Geomorphic/tectonic control of sediment discharge to the ocean: the importance of small rivers. J. Geol., 100, 525-544.

Ministry of Land, Infrastructure, Transport and Tourism (2006) http://www.mlit.go.jp/ river/basic_info/jigyo_keikaku/gaiyou/seibi/pdf/kurobe-5.pdf (in Japanese).

Mohrig, D., Heller, P., Paola, C. and Lyons, W. (2000), Interpreting avulsion process from ancient alluvial sequences: Guadalope-Matarranya system (northern Spain) and Wasatch Formation (western Colorado). Geol. Soc. Am. Bull., 112, 1787-1803. 
Muto, T. (2001) Shoreline autoretreat substantiated in flume experiments. J. Sed. Res., 71, 246-254.

Muto, T. and Steel, R.J. (1997) Principles of regression and transgression: The nature of the interplay between accommodation and sediment supply. J. Sed. Res., 67, 994-1000.

Muto, T. and Steel, R.J. (2000) The accommodation concept in sequence stratigraphy: Some dimensional problems and possible redefinition. Sed. Geol., 130, 1-10.

Muto, T. and Steel, R.J. (2004) Autogenic response of fluvial deltas to steady sea-level fall: Implications from flume-tank experiments. Geology, 32, 401-404.

Muto, T. and Steel, R.J. (2014) The autostratigraphic view of responses of river deltas to external forcing: a review of the concepts. In: From Depositional Systems to Sedimentary Successions on the Norwegian Continental Margin (Eds. A.W. Martinius, R. Ravnas, J.A. Howell, R.J. Steel and J.P. Wonham), Int. Assoc. Sedimentol. Spec. Publ., 46, 139-148.

Muto, T. and Swenson, J.B. (2005a) Large-scale fluvial grade as a non-equilibrium state in linked depositional systems: Theory and experiment. J. Geophys. Res., 110 (F), F03002, DOI: $10.1029 / 2005 J F 000284$.

Muto, T. and Swenson, J.B. (2005b) Controls on alluvial aggradation and degradation during steady fall of relative sea level: flume experiments. Proceedings of the 7th IAHR Symposium of River, Coastal and Estuarine Morphodynamics, 665-674. Taylor \& Francis Group, London.

Muto, T. and Swenson, J.B. (2006) Autogenic attainment of large-scale alluvial grade with steady sea level fall: An analog tank/flume experiment. Geology, 34, 161-164.

Muto, T., Steel, R.J. and Swenson, J.B. (2007) Autostratigraphy: A framework norm for genetic stratigraphy. J. Sed. Res., 77, 2-12.

Muto, T., Miao, H. and Parker, G. (2011) How do deltas respond as they prograde over bathymetry that varies in the transverse direction?: Results of tank experiments. RCEM 2011: Proceedings of the 7th IAHR Symposium of River, Coastal and Estuarine Morphodynamics, 563-577, Tsinghua University Press.

Nakajima, T. (2006) Hyperpycnites deposited $700 \mathrm{~km}$ away from river mouths in the central Japan Sea. J. Sed. Res., 76, 60-73.

Nakajima, T., Satoh, M. and Okamura, Y. (1998) Channel-levee complexes, terminal deep-sea fan and sediment wave fields associated with the Toyama Deep-Sea Channel system in the Japan Sea. Mar. Geol., 147, 25-41.

Nijhuis, A.G., Edmonds, D.A., Caldwell, R.L., Cederberg, J.A., Slingerland, R.L., Best, J.L., Parsons, D.R. and Robinson, R.A.J. (2015) Fluvio-deltaic avulsions during relative sea level fall. Geology, 43, 719-722. 
Nummedal, D., Riley, G.W. and Templet, P.L. (1993) High-resolution sequence architecture: A chronostratigraphic model based on equilibrium profile studies. In: Sequence Stratigraphy and Facies Associations (Eds. H.W. Posamentier, C.P. Summerhayes, B.U. Haq and G.P. Allen), Int. Assoc. Sedimentol. Spec. Publ., 18, 55- 68.

Olariu, C. and Bhattacharya, J.P. (2006) Terminal distributary channels and delta front architecture of river-dominated delta systems. J. Sed. Res., 76, 212-233.

Overeem, I., Kroonenberg, S.B., Veldkamp, A., Groenesteijn, K., Rusakov, G.V. and Svitoch, A.A. (2003) Small-scale stratigraphy in a large ramp delta: recent and Holocene sedimentation in the Volga delta, Caspian Sea. Sed. Geol., 159, 133-157.

Parker, G. (1977) Basic principles of river hydraulics. J. Hydraulics, 103, 1077-1087.

Petter, A.L. and Muto, T. (2008) Sustained alluvial aggradation and autogenic detachment of the alluvial river from the shoreline in response to steady fall of relative sea level. J. Sed. Res., 78, 98-111.

Posamentier, H.W. and Allen, G. P. (1999) Siliciclastic sequence stratigraphy. SEPM Concepts in Sedimentology and Paleontology, No. 7, 210 p.

Posamentier, H.W. and Vail, P.R. (1988) Eustatic controls on clastic deposition II — sequence and system tracts models. In: Sea-Level Changes: An Integrated Approach (Eds. C.K. Wilgus, B.S. Hastings, C.G.St.C. Kendall, H.W. Posamentier, C.A. Ross and J.C. van Wagoner), SEPM Spec. Publ., 42, 125-154.

Posamentier, H.W., Jervey, M.T. and Vail, P.R. (1988) Eustatic controls on clastic deposition I-conceptual framework. In: Sea-Level Changes: An Integrated Approach (Eds. C.K. Wilgus, B.S. Hastings, C.G.St.C. Kendall, H.W. Posamentier, C.A. Ross and J.C. van Wagoner), SEPM Spec. Publ., 42, 109-124.

Postma, G., Kleinhans, M.G., Meijer, P.TH. and Eggenhuisen, J.T. (2008) Sediment transport in analogue flume models compared with real-world sedimentary systems: a new look at scaling evolution of sedimentary systems in a flume. Sedimentology, 55, 15411557. doi: 10.1111/j.1365-3091.2008.00956.x

Powell, E.J., Kim, W. and Muto, T. (2012) Varying discharge controls on timescales of autogenic storage and release processes in fluvio-deltaic environments: Tank experiments. J. Geophy. Res., 117, F02011. doi:10.1029/2011JF002097.

Reitz, M.D. and Jerolmack, D.J. (2012) Experimental alluvial fan evolution: Channel dynamics, slope controls, and shoreline growth. J. Geophys. Res., 117, F02021, doi:10.1029/2011JF002261.

Reitz, M.D., Jerolmack, D.J. and Swenson, J.B. (2010) Flooding and flow path selection on alluvial fans and deltas. Geophys. Res. Lett., 37, L06401, doi: 10.1029/2009GL041985 
Ritter, D.F. (1967) Terrace development along the front of the Beartooth Mountains, southern Montana, Wyoming. Geol. Soc. Am. Bull., 78, 467-484.

Schumm, S.A. (1977) The Fluvial System. John Wiley, Hoboken, N. J., 338 pp.

Shanley, K.W. and McCabe, P.J. (1994) Perspectives on the sequence stratigraphy of continental strata. AAPG Bull., 78, 544-568.

Straub, K., Paola, C., Mohrig, D., Wolinsky, M. and George, T. (2009) Compensational stacking of channelized sedimentary deposits. J. Sed. Res., 79, 673-688.

Swenson, J.B. and Muto, T. (2007) Response of coastal plain rivers to falling relative sea-level: allogenic controls on the aggradational phase. Sedimentology, 54, 207-221.

Thorne, J.A. and Swift, D.J.P. (1991) Sedimentation on continental margins, II: application of the regime concept. In: Shelf Sand and Sandstone Bodies (Eds. D.J.P. Swift, G.F. Oertel, R.W. Tillman and J.A. Thorne), Int. Assoc. Sedimentol. Spec. Publ., 14, 33-58.

Tomer, A., Muto, T. and Kim, W. (2011) Autogenic Hiatus in fluviodeltaic successions: geometrical modeling and physical experiments. J. Sed. Res., 81, 207-217.

Van Dijk, M., Postma, G. and Kleinhans, M.G. (2009) Autocyclic behaviour of fan deltas: an analogue experimental study. Sedimentology, 56, 1569-1589 doi:

10.1111/j.1365-3091.2008.01047.x

Van Heijst, M.W.I.M. and Postma, G. (2001) Fluvial response to sea-level changes: a quantitative analogue, experimental approach. Basin Res., 13, 269-292.

Veldkamp, A.A. (1992) A3-D model of Quaternary terrace development, simulations of terrace stratigraphy and valley asymmetry: A case study for the Allier terraces (Limagne, France), Earth Surf. Proc. Land., 17, p. 487-500.

Whipple, K.X., Parker, G., Paola, C. and Mohrig, D. (1998) Channel dynamics, sediment transport, and the slope of alluvial fans: Experimental study. J. Geol., 106, 677-694.

\section{APPENDIX 1: DERIVATION OF EQUATIONS 6 AND 7}

On the assumption that the entire sediment supplied through a feeder bedrock river during a period of time $t$ is consumed to build a delta, the following equation of mass balance holds true:

$$
V_{\text {subacial }}+V_{\text {subaqueons }}=\int_{0}^{t} Q_{\mathrm{s}} d t
$$

where $V_{\text {subaerial }}$ is the sediment volume of the alluvial topset (the deposit that lies above the base level), $V_{\text {subaqueous }}$ represents the subaqueous part of the delta (the deposit that lies below the base level), and $Q_{\mathrm{s}}$ is upstream sediment discharge measured at the ABT. 
For simplification, we assume: (1) $Q_{\mathrm{s}}$ is constant through time, (2) a delta plain is always attached to a vertical wall behind $\left(\gamma=90^{\circ}\right)$ and has a central angle of $\lambda$ in radians, (3) the base level remains stationary, and (4) the basin floor is horizontal $\left(\phi=0^{\circ}\right)$ with a constant water depth of $h$ (Fig. A1). If the delta retains its overall geometry with constant angle parameters during progradation from the onset of the delta growth, the following equation of mass balance holds true:

$$
\begin{aligned}
& V_{\text {subaerial }}=\frac{\alpha \lambda}{6} x^{3} \\
& V_{\text {subaqueous }}=\frac{\lambda}{2} h x^{2}+\frac{\lambda}{2 \beta} h^{2} x+\frac{\lambda}{6 \beta^{2}} h^{3}
\end{aligned}
$$

where $x$ is the deltaplain radius, $\alpha$ is the tangent of the mean alluvial topset slope and $\beta$ is tangent of the mean foreset slope. Equation A1 is thus modified as:

$$
\frac{\alpha \lambda}{6} x^{3}+\frac{\lambda}{2} h x^{2}+\frac{\lambda}{2 \beta} h^{2} x+\frac{\lambda}{6 \beta^{2}} h^{3}=Q_{\mathrm{s}} t
$$

In this geometrical setting, sediment accumulation inevitably occurs in both subaerial and subaqueous parts of the delta, and thus the alluvial system can never attain grade in a strict sense. However, the present simple modelling provides an insightful implication as to the effect of basin water depth upon approaching grade.

By differentiating Eq. A4 with respect to $t$, an overall progradation rate $R_{\text {pro }}$ and an overall alluvial aggradation rate $R_{\text {agg }}$ are found:

$$
\begin{aligned}
& R_{\mathrm{pro}}=\frac{d x}{d t}=\frac{2 \beta Q_{\mathrm{s}}}{\lambda\left(\alpha \beta x^{2}+2 \beta h x+h^{2}\right)} \\
& R_{\mathrm{agg}}=\alpha \frac{d x}{d t}=\frac{2 \alpha \beta Q_{\mathrm{s}}}{\lambda\left(\alpha \beta x^{2}+2 \beta h x+h^{2}\right)}
\end{aligned}
$$

In the case that $h$ is negligibly small compared with $(\alpha \beta)^{0.5} x$, i.e. the basin water is extremely shallow, the corresponding values of $R_{\text {pro }}$ and $R_{\text {agg }}$ are given by

$$
\begin{aligned}
& R_{\mathrm{pro}_{h-1}}=\frac{2 Q_{\mathrm{s}}}{\alpha \lambda x^{2}} \\
& R_{\mathrm{ggg}_{h-1}}=\frac{2 Q_{\mathrm{s}}}{\lambda x^{2}}
\end{aligned}
$$

Equations A5 and A6 can be made dimensionless by dividing by Eqs. A7 and A8, respectively: 


$$
\begin{aligned}
& R_{\mathrm{pro}^{*}}=\frac{R_{\mathrm{pro}}}{R_{\mathrm{pro}_{h-0}}}=\frac{1}{1+2 h_{*}+\alpha_{*} h_{*}^{2}} \\
& R_{\mathrm{agg} *}=\frac{R_{\mathrm{ggg}}}{R_{\mathrm{ggg}_{h-0}}}=\frac{1}{1+2 h_{*}+\alpha_{*} h_{*}^{2}}
\end{aligned}
$$

where $h *$ is the dimensionless basin water depth (Eq. 5) and $\alpha *$ is the alluvial slope normalized with $\beta$, defined as

$$
\alpha_{*}=\frac{\alpha}{\beta}
$$

As is evident from Eqs. A9 and A10, the rates of shoreline-averaged delta progradation and overall alluvial aggradation are both markedly affected by the basin water depth. To account for this relationship, the grade index $G_{\text {index }}$ is here defined to quantify the effect of the basin water depth, to encompass $R_{\text {pro* }}$ and $R_{\text {agg* }}$, and to denote how closely the feeder alluvial system is graded:

$$
G_{\text {index }}=R_{\mathrm{pro}^{*}}=R_{\text {agg* }}=\frac{1}{1+2 h_{*}+\alpha_{*} h_{*}^{2}}
$$

Clearly, the alluvial topset river of the delta approaches grade as $h *$ increases towards $+\infty$, and perfect aggradation as $h *$ decreases towards 0 . If basin water depth in front of the delta is extremely large ( $h *>>1$ ) so that the feeder alluvial system is graded ( $\left.G_{\text {index }} \sim 0\right)$, the delta does not prograde, even though all the sediment that is supplied to the ABT bypasses the alluvial reaches.

The grade index can also encompass the rate of mean channel migration along the shoreline. Delta distributary channels can change location by two different modes: channel shifting and avulsion. The time scale of alluvial river avulsion $\tau_{\mathrm{A}}$ can be approximated as the time interval that is required for the river to aggrade one average channel depth $h_{\mathrm{c}}$ (Mohrig et al., 2000; Jerolmack \& Mohrig, 2007; Reitz et al. 2010):

$$
\tau_{\mathrm{A}}=\frac{h_{\mathrm{c}}}{R_{\mathrm{agg}}}
$$

Although this time scale is not one that is associated specifically with the actual avulsion times of the river course, it can be useful for the present geometric considerations. The avulsion frequency of the river system $f_{\mathrm{A}}$ is then given by

$$
f_{\mathrm{A}}=\frac{N}{\tau_{\mathrm{A}}}=\frac{N R_{\mathrm{agg}}}{h_{\mathrm{c}}}
$$

where $N$ is the number of active channels. When $h \sim 0$, the corresponding values are given by 


$$
\begin{gathered}
\tau_{\mathrm{A}_{h-0}}=\frac{h_{\mathrm{c}}}{R_{\mathrm{agg} h-0}}=\frac{\lambda h_{\mathrm{c}} x^{2}}{2 Q_{\mathrm{s}}} \\
f_{\mathrm{A}_{h-0}}=\frac{N}{\tau_{\mathrm{A}_{h-1}}}=\frac{2 N Q_{\mathrm{s}}}{\lambda h_{\mathrm{c}} x^{2}}
\end{gathered}
$$

Equations A13 and A14 can be made dimensionless by dividing with Eqs. A15 and A16, respectively:

$$
\begin{aligned}
& \tau_{\mathrm{A}^{*}}=\frac{\tau_{\mathrm{A}}}{\tau_{\mathrm{A}_{h-0}}}=\frac{R_{\mathrm{xgg}_{h_{h-0}}}}{R_{\mathrm{agg}}}=\left(R_{\mathrm{ggg}^{*}}\right)^{-1}=\left(G_{\text {index }}\right)^{-1} \\
& f_{\mathrm{A}^{*}}=\frac{f_{\mathrm{A}}}{f_{\mathrm{A}_{h-1}}}=R_{\mathrm{agg}^{*}}=G_{\text {index }}
\end{aligned}
$$

Thus, if the feeder channel is graded ( $G_{\text {index }} \sim 0$ ), $\tau_{\mathrm{A}^{*}} \sim+\infty$ and $f_{\mathrm{A}^{*}} \sim 0$, channel avulsion no longer occurs.

Jerolmack \& Mohrig (2007) also suggest a time scale for channel shifting $\tau_{\text {s, }}$ which is given by

$$
\tau_{\mathrm{s}}=\frac{B}{v_{\mathrm{s}}}
$$

where $B$ is the average width of the active channels and $v_{\mathrm{s}}$ is the bank erosion rate, which is approximately equal to the migration rate of the active shoreline $R_{\mathrm{mig}}$ if measured along the shoreline:

$$
R_{\text {mig }} \sim v_{\mathrm{s}}
$$

The lateral shifting of distributary channels occurs because of a local decrease of channel slope (Olariu \& Bhattacharya, 2006; Straub, 2009), which can arise from the basinward extension of the channel mouth, i.e. shoreline progradation. Thus, $R_{\text {pro }}$ will positively correlate to $R_{\mathrm{mig}}$, which implies the following relationship:

$$
R_{\text {mig }}=\Omega R_{\text {pro }}=\alpha^{-1} \Omega R_{\text {agg }}=\alpha^{-1} \Omega R_{\mathrm{agg}_{k-0}} G_{\text {index }}
$$

where $\Omega$ is the dimensionless positive coefficient that will be related to the parameters, including the grain-size distribution or the vegetation of flood plains. In fact, the experimental data that were obtained by Muto et al. (2011) support a linear correlation between $R_{\text {mig and }}$ $R_{\text {agg }}$ (Fig. A2), where $\Omega$ is on the order of $10^{1}$ for the given experimental conditions, i.e. $R_{\mathrm{mig}} \sim$ $10^{1} R_{\text {pro }} \sim 10^{2} R_{\text {agg. }}$. If this linear relationship holds true even when $h \sim 0$, the dimensionless rate of channel migration along the shoreline is given by: 


$$
R_{\text {mig* }}=\frac{R_{\text {mig }}}{R_{\text {mig }_{h-0}}}=G_{\text {index }}
$$

where

$$
R_{\text {mig }_{h-1}}=\Omega R_{\text {pro }_{h-1}}=\alpha^{-1} \Omega R_{\mathrm{agg}_{h-1}}
$$

On the other hand, the time scale of channel shifting (Eq. A19) can be rewritten as

$$
\begin{gathered}
\tau_{\mathrm{s}}=\frac{B}{v_{\mathrm{s}}}=\frac{B}{\Omega R_{\mathrm{pro}}}=\frac{\alpha B}{\Omega R_{\mathrm{agg}}} \\
\tau_{\mathrm{s}_{h-1}}=\frac{B}{\Omega R_{\mathrm{pro}_{h-1}}}=\frac{\alpha B}{\Omega R_{\mathrm{agg}_{h-1}}}
\end{gathered}
$$

The dimensionless time scale of channel shifting $\tau_{s^{*}}$ is thus given as follows:

$$
\tau_{\mathrm{s}^{*}}=\frac{\tau_{\mathrm{s}}}{\tau_{\mathrm{s}_{h-0}}}=\frac{R_{\mathrm{agg}_{h-0}}}{R_{\mathrm{agg}}}=\left(R_{\mathrm{agg}^{*}}\right)^{-1}=\left(G_{\text {index }}\right)^{-1}
$$

Considering the time scale of channel shifting $\tau_{\mathrm{r}}$, which reflects the mean recurrence period of a particular channel to a particular position, may also make sense:

$$
\begin{aligned}
& \tau_{\mathrm{r}}=\frac{\lambda x}{R_{\text {mig }}}=\frac{\alpha \beta \lambda x}{\Omega R_{\text {agg }}} \\
& \tau_{\mathrm{\tau}_{h-1}}=\frac{\lambda x}{R_{\text {mig }_{h-1}}}=\frac{\alpha \beta \lambda x}{\Omega R_{\mathrm{agg}_{h-1}}}
\end{aligned}
$$

The dimensionless recurrence time is thus given by

$$
\tau_{\mathrm{r}^{*}}=\frac{\tau_{\mathrm{r}}}{\tau_{\mathrm{r}_{h-0}}}=\frac{R_{\mathrm{agg}_{h-0}}}{R_{\mathrm{ggg}}}=\left(G_{\text {index }}\right)^{-1}
$$

If the alluvial channel is graded ( $G_{\text {index }} \sim 0$ ), it does not migrate but is stabilized in a particular location $\left(R_{\text {mig* }} \sim 0\right)$ so that the characteristic time scale for channel shifting takes an infinite value $\left(\tau_{s^{*}} \sim+\infty\right)$; it takes an infinite time for the channel to recur where it previously was. All the above relations are thus reduced to Eq. 7.

\section{APPENDIX 2: DERIVATION OF EQUATIONS 9 AND 11}

The topographic setting for the R series runs is significantly different from the one that is assumed for Eq. 6, from the point-of-view that (1) the hinterland basement is not vertical but gently inclined ( $\gamma \sim 0.364$ in tangent), (2) the basin floor landward of the overfall is not horizontal but tilts basinward at a constant slope of $\phi$ ( 0.213 in tangent), and thus (3) the basin water depth in front of a delta is not spatially uniform but increases basinward 
proportional to $x$ (Eq. 9). With these slope conditions, the dimensionless basin water depth in front of a delta takes a constant value that is determined only with the following geometrical parameters:

$$
h_{*}=\frac{h}{\alpha x}=\frac{\beta \phi}{\alpha(\beta-\phi)}
$$

For the topographic conditions that were adopted in the R series runs, the subaerial part of the delta is approximated as an oblique cone the bottom plane of which is a sector having a central angle of $\pi$ in radians (i.e. semicircle with an area of $\pi x^{2} / 2$ ). The height of the cone's apex is given as $\alpha \gamma x /(\gamma \square(x)$. The first term on the left side of Eq. A1 is thus expressed as:

$$
V_{\text {subaerial }}=\frac{\alpha \gamma}{6(\gamma-\alpha)} \pi x^{3}
$$

The subaqueous part of the delta is in a shape of part of frustum formed from a cone, the volume of which is calculated by:

$$
V_{\text {subaqueous }}=\int_{0}^{h} S(\eta) d \eta
$$

where $\eta$ is the water depth of a foreset surface $(0 \leq \eta \leq h)$ and $S(\eta)$ is the horizontal cross-section area of the delta's subaqueous deposit at the depth $\eta$. The geometrical form of $S(\eta)$ is represented as circular segment, i.e. part of a sector which is cut off from the rest of the sector by chord. In Fig. A3, the sector has a radius of $x_{\eta}$ and a central angle of $2 \sigma_{\eta}$ in radians, which are specified with $x, \beta, \phi$ and $\eta$ :

$$
\begin{aligned}
& x_{\eta}=x+\frac{\eta}{\beta} \\
& \sigma_{\eta}=\arccos \left(\frac{\beta \eta}{\beta \phi x+\phi \eta}\right)
\end{aligned}
$$

The circular segment $A_{\eta} X_{\eta} B_{\eta}$ is the rest of the sector $O_{\eta} A_{\eta} X_{\eta} B_{\eta}$ from which the isosceles triangle $\mathrm{O}_{\eta} \mathrm{A}_{\eta} \mathrm{B}_{\eta}$ is removed. Thus, $S(\eta)$ is calculated by:

$$
S(\eta)=\sigma_{\eta}\left(x_{\eta}\right)^{2}-\frac{\sigma_{\eta}}{\sqrt{1+\left(\sigma_{\eta}\right)^{2}}}\left(\frac{\eta}{\phi}\right) x_{\eta}
$$

Thus, the mass balance relationship for the assumed topographic setting is given as:

$$
\frac{\alpha \gamma}{6(\gamma-\alpha)} \pi x^{3}+\int_{0}^{h}\left\{\sigma_{\eta}\left(x_{\eta}\right)^{2}-\frac{\sigma_{\eta}}{\sqrt{1+\left(\sigma_{\eta}\right)^{2}}}\left(\frac{\eta}{\phi}\right) x_{\eta}\right\} d \eta=Q_{s} t
$$


Finding an analytical solution to Eq. A36 is difficult, but a numerical solution can be found. Because of the assumed topographic conditions, the whole deltaic deposit does not change in shape with time, as reflected in the constant ratio of $x$ to $h$ (Eq. 9). Thus, the sediment volume ratio $\kappa$ of the subaqueous part to the subaerial part (Eq. 10) is kept constant throughout the progradation of the delta:

$$
\frac{V_{\text {subaqueous }}}{V_{\text {subaerial }}}=\kappa=\text { const }
$$

which is easily confirmed through numerical simulation. Equation A36 can therefore be reduced to

$$
\frac{\alpha \gamma}{6(\gamma-\alpha)} \pi(1+\kappa) x^{3}=Q_{\mathrm{s}}
$$

From this simple expression, $R_{\mathrm{pro}}, R_{\mathrm{agg}}, R_{\mathrm{mig}}$ and $f_{\mathrm{A}^{*}}$ are found through a similar procedure as considered in Appendix 1:

$$
R_{\mathrm{pro}^{*}}=R_{\mathrm{xgg}^{*}}=R_{\mathrm{mig}}=f_{\mathrm{A}^{*}}=\frac{1}{1+\mathrm{\kappa}}
$$

Grade index applicable to the R series runs can thus be defined with Eq. 11. 


\section{Captions}

Table 1. Experimental conditions and results for the runs in the R series, the F series and the M series.

Table 2. Dataset of the Kurobegawa River.

Figure 1. Three different methods of building a graded alluvial river in deltaic settings. A: Allogenic grade, which is attained by a non-equilibrium response to decelerating sea level fall in a moving-boundary setting where the alluvial slope is gentler than the basin slope. B: Autogenic grade, which is attained through an equilibrium response to constant sea level fall in a moving boundary setting where the alluvial slope is equal to the basin slope. C: Forced grade, which is attained through an equilibrium response to a stationary sea level in a fixed boundary setting.

Figure 2. How to describe the locations of active shoreline and temporal changes. The azimuths $\theta$ at both ends of an active shoreline segment are given as angular distances that are measured from one of the vertical walls $\left(\theta=0^{\circ}\right)$ and plotted against time. Paired plots are connected with a bar. By drawing all the $\theta$ data through run time, the trajectories of active shorelines can be graphically represented.

Figure 3. Sequential photo images of Run R1, during which a delta built up on a uniform basement surface that gently tilts basinward. The red lines indicate active shoreline segments.

Figure 4. Trajectory diagrams of the active shoreline segments (left column) and the ABT (right column) that were obtained from the R series of runs. During each run, (1) the active shoreline segments continually migrated laterally and were never more than momentarily stationary, and (2) the ABT showed a tendency to migrate landward with insignificant landward oscillations.

Figure 5. Sequential photo images of Run F1, during which a delta was unable to prograde beyond a submerged overfall. Soon after the delta toe reached the overfall, a single large channel stabilized in the axial part of the delta plain. The red lines indicate active shoreline segments. 
Figure 6. Trajectory diagrams of the active shoreline segments (left column) and the ABT (right column) that were obtained from the F series runs. In each run, (1) the behaviour of the active shoreline segments changed drastically soon after the delta toe had reached the overfall, and (2) the ABT simultaneously came to a halt after insignificant basinward migration.

Figure 7. Temporal deviation in the active shoreline position and ABT location from the mean, which were obtained from Runs F1, F2, and F3 after the delta toes reached the overfall. The ABT locations (landward positive) are made dimensionless by dividing by the delta plain's radius. The lateral excursion of the shoreline represents a spatial range of active shoreline azimuths, which is given by the maximum $\theta\left(\theta_{\max }\right)$ minus the minimum $\theta\left(\theta_{\min }\right)$.

Figure 8. An image of the delta from Run F4 that was taken some time after the delta toe had reached the overfall. Note the presence of well-developed paired terraces along the axial channel. The following tendencies were found: (1) higher (i.e. older) terraces had higher slopes, and thus (2) the present active river bed has the lowest slopes at any time in the evolution of the alluvial system. These terraces are autogenic because the dynamic forcing ( $Q_{\mathrm{w}}, Q_{\mathrm{s}}$, base level) was kept constant during the run.

Figure 9. Sequential photo images of Run M1, where a delta was built with constant base-level fall. A particular delta lobe extended linearly basinward without any significant lateral shifting.

Figure 10. Sequential photo images of Run M2, where a deltaic lobe extended over $3 \mathrm{~m}$ basinward with constant base-level fall as in Run M1, but in a larger tank.

Figure 11. Trajectory diagrams of the active shoreline segments (left) and the ABT (right) that were obtained from the $\mathrm{M}$ series runs. In each run, (1) the lateral extent of the migration of active shoreline segments progressively converged to the axial position $\left(\theta \sim 90^{\circ}\right)$, and (2) the landward migration of the ABT decelerated and came to a stop.

Figure 12. Dimensionless linear-scale trajectory diagrams of the active shoreline segments (left) and the ABT (right) that were obtained from the M series runs. The alluvial system that was observed in Run M1 only appears to represent a significant early stage during its evolution towards a graded state. 
Figure 13. Topographic setting of the fan deltas/alluvial fans on the Japan Sea coast of central Japan. Most of the feeder river mouths have direct connections with submarine canyons in the Toyama Deep Sea Channel. $\mathrm{J}$ = Joganjigawa, $\mathrm{H}$ = Hayatsukigawa, $\mathrm{K}=$ Katakaigawa, $\mathrm{Kr}=$ Kurobegawa. Simplified from Nakajima et al. (1998).

Figure 14. Downstream profiles of terraces and present river beds along the axial channels of the Kurobegawa, the Katakaigawa, the Hayatsukigawa and the Joganjigawa. Numerical values for alluvial slopes $(\alpha)$ and grade indexes $\left(G_{\text {index }}\right)$ are provided. In each river system, higher terraces have higher slopes. The ages of the terraces are based on chronological data by Matsuura et al. (2007) and Fujii et al. (2011).

Figure A1. Schematic illustration of a delta that is assumed in geometrical modelling. See text for a detailed explanation.

Figure A2. Linear relationship between $R_{\mathrm{mig}}$ and $R_{\mathrm{agg}}$ that was obtained from the experimental

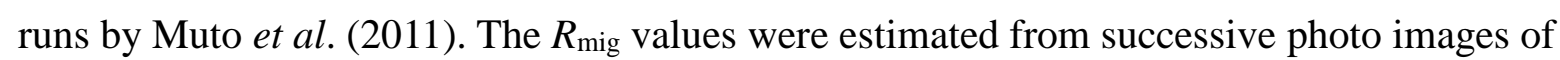
the run, and the $R_{\text {agg }}$ values were provided by calculation with other parameters, including the grade index. The dataset was extracted from the special status of the delta plain which only had a single large channel that reflected the entire sediment discharge (i.e. $Q_{\text {s }}$ ).

Figure A3. The 3D shape of the subaqueous deposit of the delta which progrades above a basement floor having a constant slope of $\phi(<\beta)$. A: Oblique view. B: Horizontal cross section of the deposit at depth $\eta$. C: Vertical cross section. The deposit can be approximated with part of a truncated cone that appears as a circular segment in horizontal section and a triangle in vertical section. 
Table 1

\begin{tabular}{|c|c|c|c|c|c|c|c|c|c|}
\hline Run & $\mathrm{R} 1$ & $\mathrm{R} 2$ & $\mathrm{R} 3$ & F1 & $\mathrm{F} 2$ & F3 & $\mathrm{F} 4$ & M1 & M2 \\
\hline $\begin{array}{l}\text { Boundary condition } \\
\text { Base level }\end{array}$ & $\begin{array}{l}\text { moving } \\
\text { stationary }\end{array}$ & $\begin{array}{l}\text { moving } \\
\text { stationary }\end{array}$ & $\begin{array}{l}\text { moving } \\
\text { stationary }\end{array}$ & $\begin{array}{l}\text { downstream-fixed } \\
\text { stationary }\end{array}$ & $\begin{array}{l}\text { downstream-fix } \\
\text { stationary }\end{array}$ & $\begin{array}{l}\text { ed downstream-fixed } \\
\text { stationary }\end{array}$ & $\begin{array}{l}\text { downstream-fixed } \\
\text { stationary }\end{array}$ & $\begin{array}{c}\text { moving } \\
\text { constant fall }\end{array}$ & $\begin{array}{l}\text { moving } \\
\text { constant fall }\end{array}$ \\
\hline Rate of base level fall: $R_{\mathrm{blf}}\left(\mathrm{cm} \mathrm{s}^{-1}\right)$ & - & - & - & - & - & - & - & 0.00124 & 0.00353 \\
\hline Hinterland basement slope: $\gamma$ & 0.364 & 0.364 & 0.364 & 0.364 & 0.364 & 0.364 & 0.364 & 0.2160 & 0.331 \\
\hline Subaqueous basin slope: $\phi$ & 0.213 & 0.213 & 0.213 & 0.125 & 0.132 & 0.0871 & 0.126 & 0.070 & 0.059 \\
\hline Run time: $t$ (s) & 6025 & 5580 & 4995 & 4815 & 4485 & 4485 & 5520 & 2985 & 6570 \\
\hline Water discharge: $Q_{\mathrm{w}}\left(\mathrm{cm}^{3} \mathrm{~s}^{-1}\right)$ & 4.55 & 3.81 & 6.50 & 4.62 & 4.55 & 4.63 & 3.81 & 28.27 & 28.41 \\
\hline Sediment discharge: $Q_{\mathrm{s}}\left(\mathrm{cm}^{3} \mathrm{~s}^{-1}\right)$ & 1.178 & 1.178 & 1.178 & 1.178 & 1.178 & 1.178 & 1.178 & 0.2928 & 1.131 \\
\hline Water/sediment ratio: $Q_{\mathrm{w}} / Q_{\mathrm{s}}$ & 3.86 & 3.23 & 5.52 & 3.92 & 3.86 & 3.93 & 3.23 & 96.55 & 25.12 \\
\hline Mean alluvial slope (measured): $\alpha$ & 0.245 & 0.275 & 0.222 & 0.215 & 0.249 & 0.188 & 0.214 & 0.070 & 0.060 \\
\hline Mean foreset slope (assumed): $\beta$ & 0.490 & 0.490 & 0.490 & 0.490 & 0.490 & 0.490 & 0.490 & 0.490 & 0.490 \\
\hline
\end{tabular}


Table 2

\begin{tabular}{|c|c|c|c|c|}
\hline parameter & notation & unit & numerical value & data source \\
\hline "age of the oldest terrace & 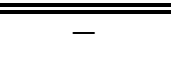 & kaBP & $20-30$ & "Matsuura et al. (2007) \\
\hline drainage area & $A$ & $\mathrm{~km}^{2}$ & 667 & MLIT (2014) \\
\hline alluvial slope & $\alpha$ & - & 0.0172 & measured \\
\hline foreset slope & $\beta$ & - & 0.268 & Nakajima (2006) \\
\hline central angle & $\lambda$ & - & 0.79 & measured \\
\hline delta plain radius & $x$ & $\mathrm{~km}$ & 13.3 & assumed \\
\hline sediment yield intensity & $q_{\text {sy }}$ & $\mathrm{m}^{3} \mathrm{~km}^{-2}$ year $^{-1}$ & 1929 & Kobayashi \& Tanaka (2012) \\
\hline sediment supply rate & $Q_{\mathrm{s}}$ & $m^{3}$ year $^{-1}$ & $1.29 \times 10^{6}$ & $Q_{\mathrm{s}}=q_{\mathrm{sy}} \mathrm{A}$ \\
\hline channel depth at flooding & $h_{\mathrm{c}}$ & $\mathrm{m}$ & 3 & MLIT (2014) \\
\hline avulsion time scale for $h \sim 0$ & $\tau_{\mathrm{A} h \sim 0}$ & year & $3.2 \times 10^{3}$ & Equation 15 \\
\hline basin water depth & $h$ & $\mathrm{~m}$ & 1000 & Nakajima (2006) \\
\hline dimensionless basin water depth & $h_{*}$ & - & 4.37 & Equation 5 \\
\hline grade index & $G_{\text {index }}$ & - & 0.00325 & Equation 6 \\
\hline avulsion time scale & $\tau_{\mathrm{A}}$ & year & $5 \times 10^{5}$ & Equation 16 \\
\hline
\end{tabular}

MLIT: Ministry of Land, Infrastracture, Transport and Turism 
Fig 1

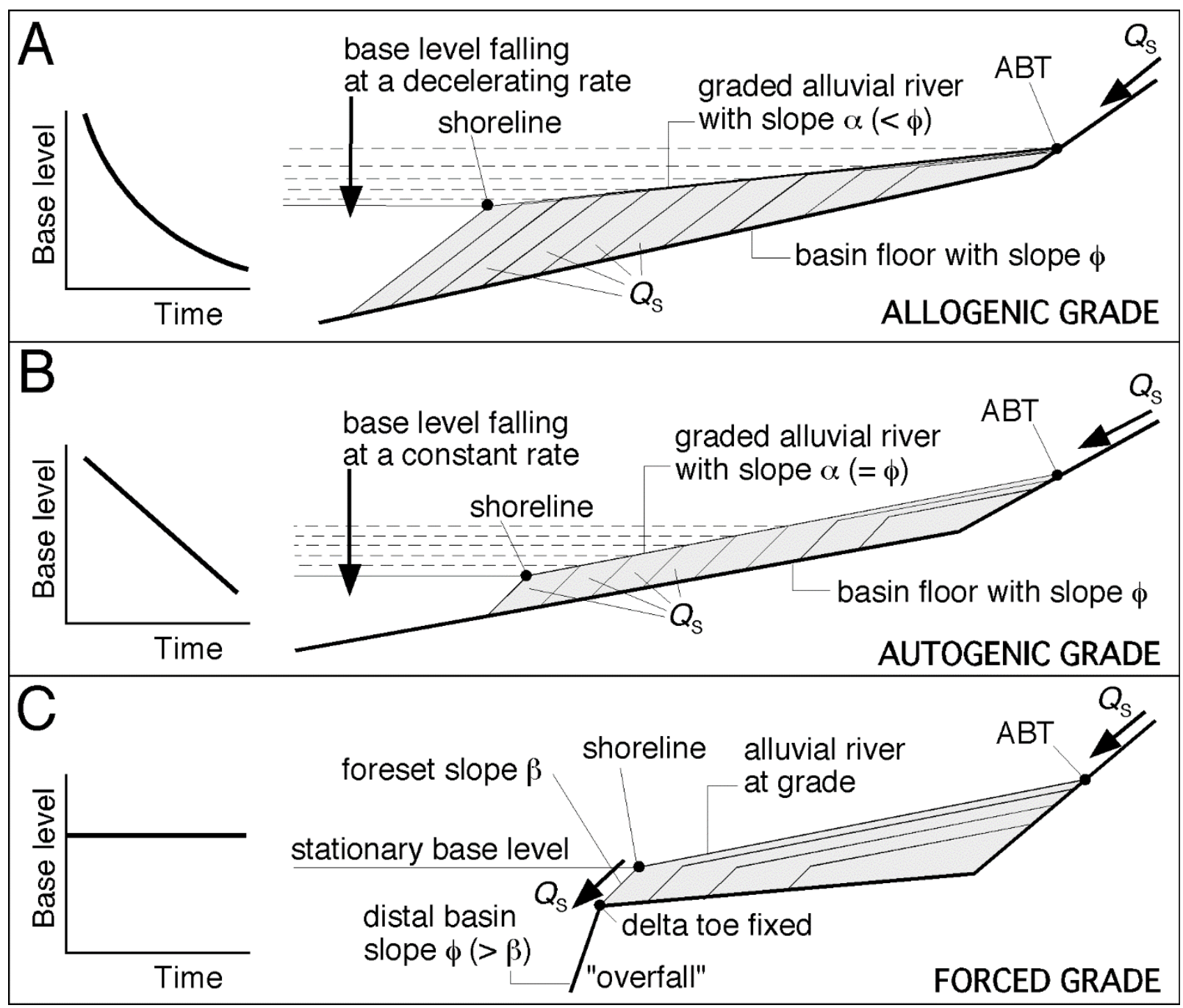


Fig 2
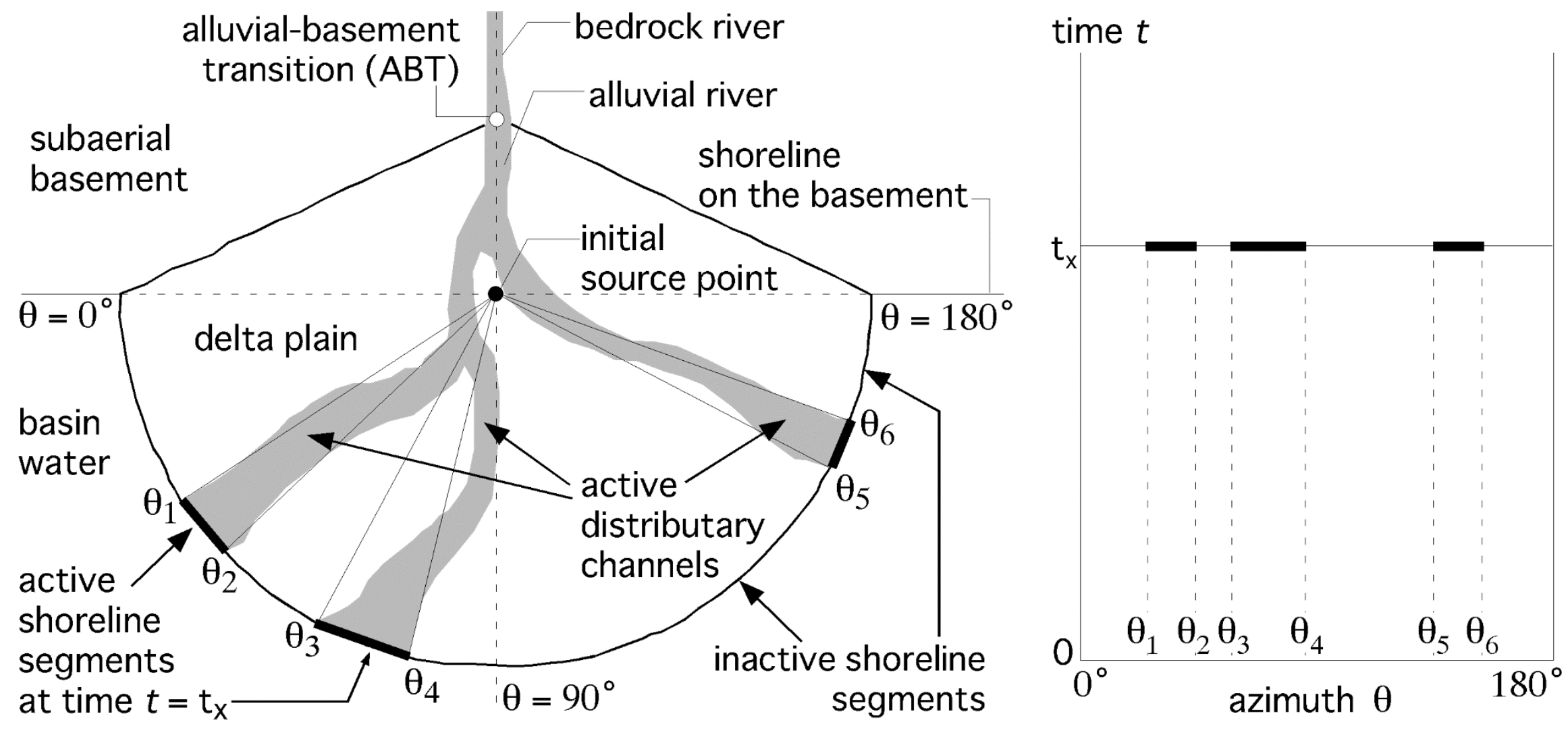
Fig 3
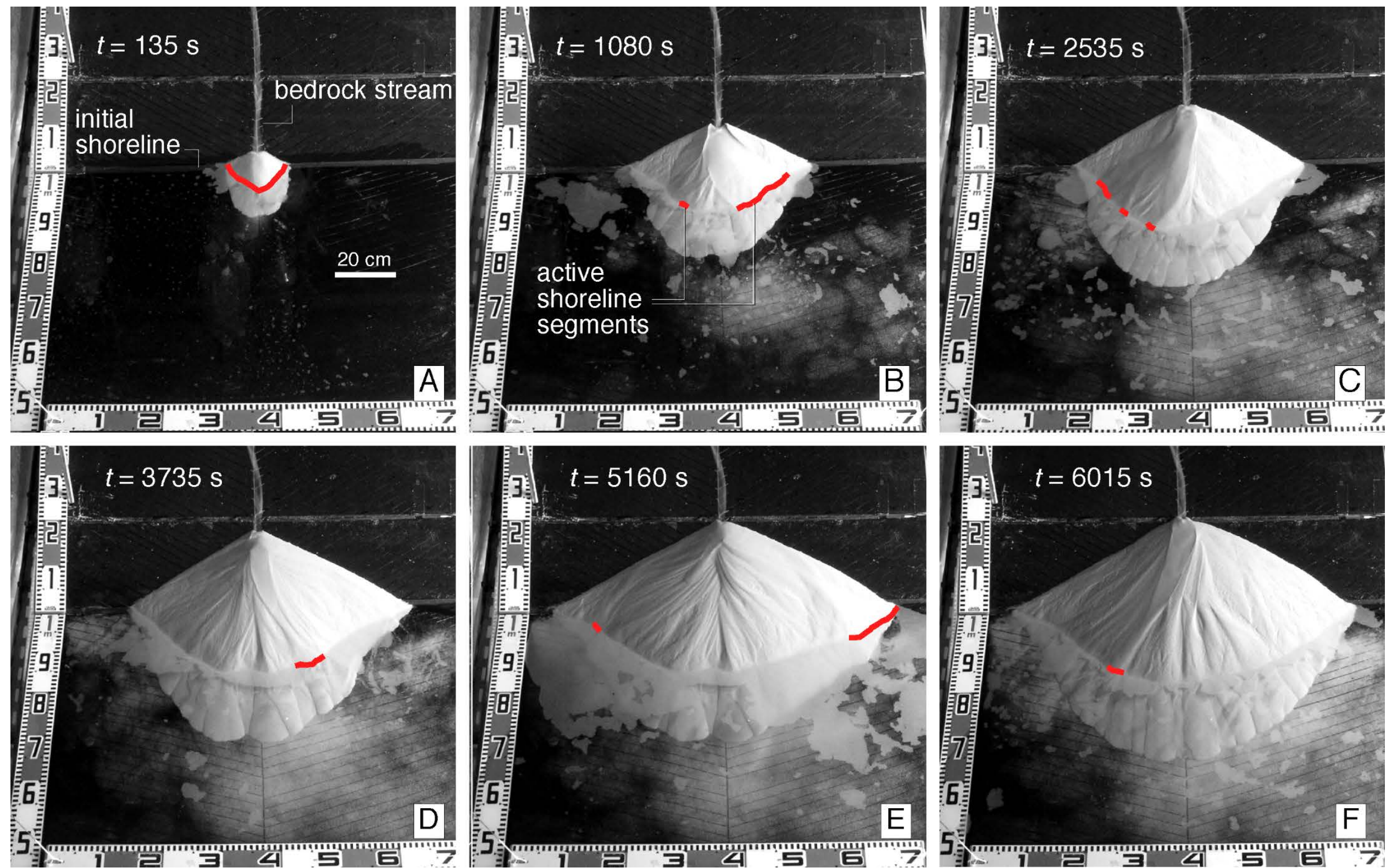
Fig 4
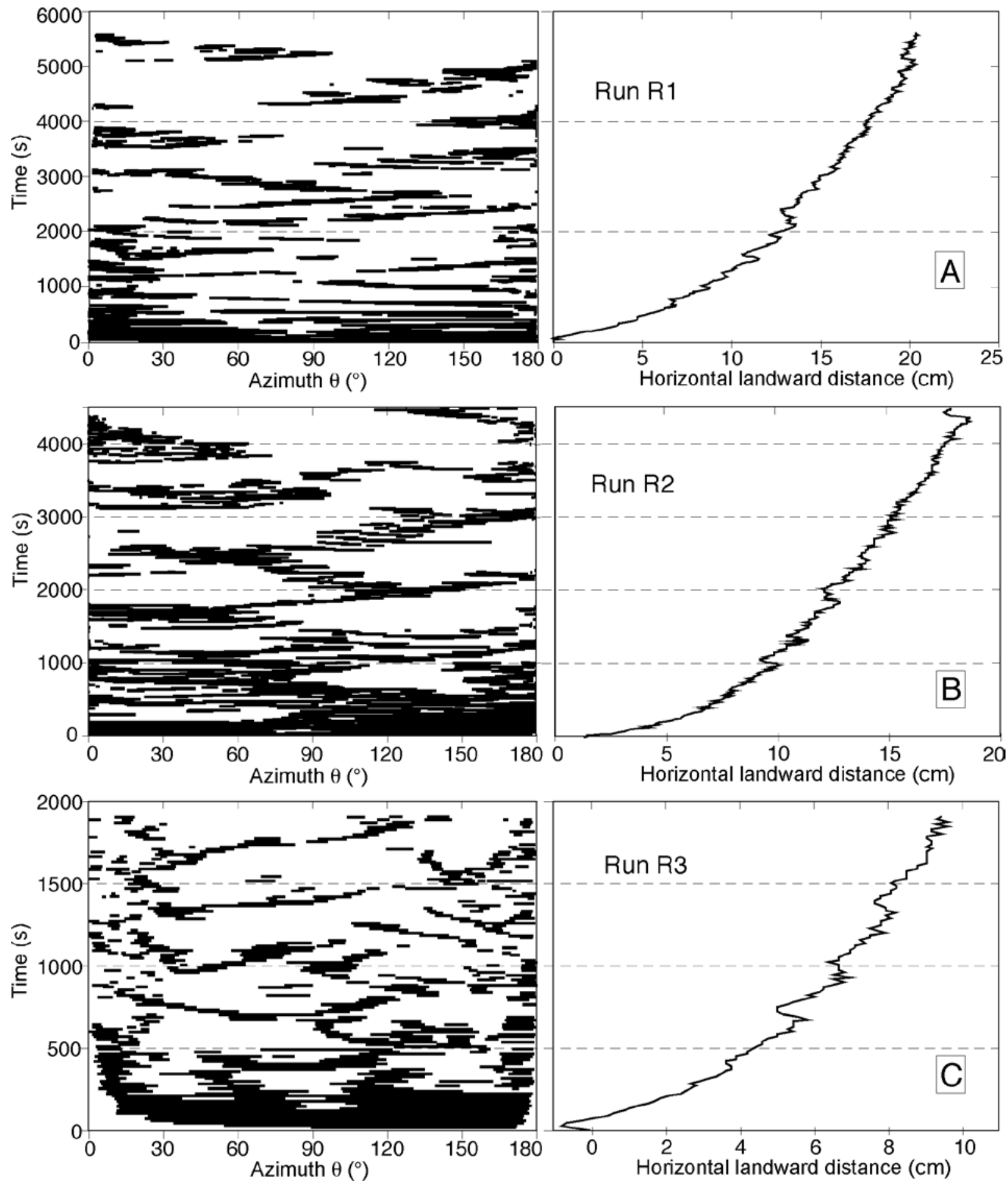
Fig 5
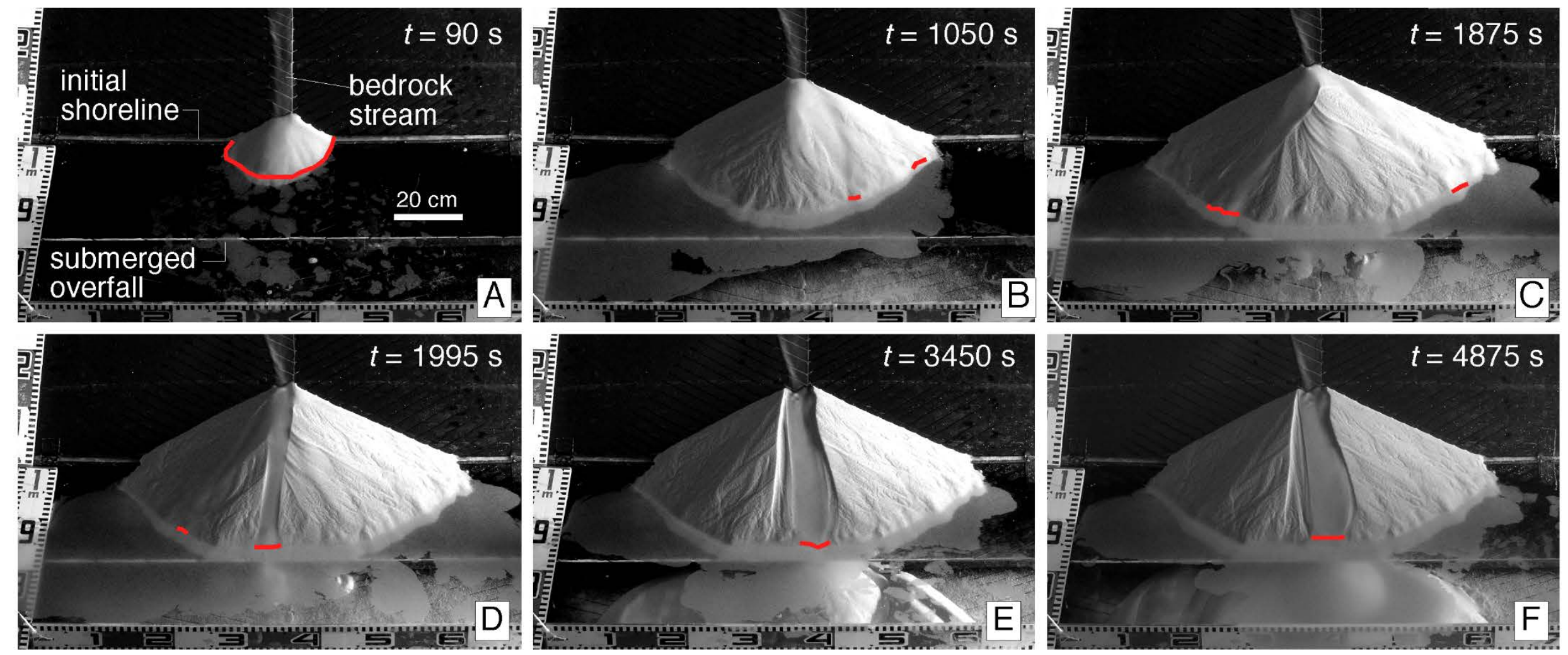


\section{Fig 6}
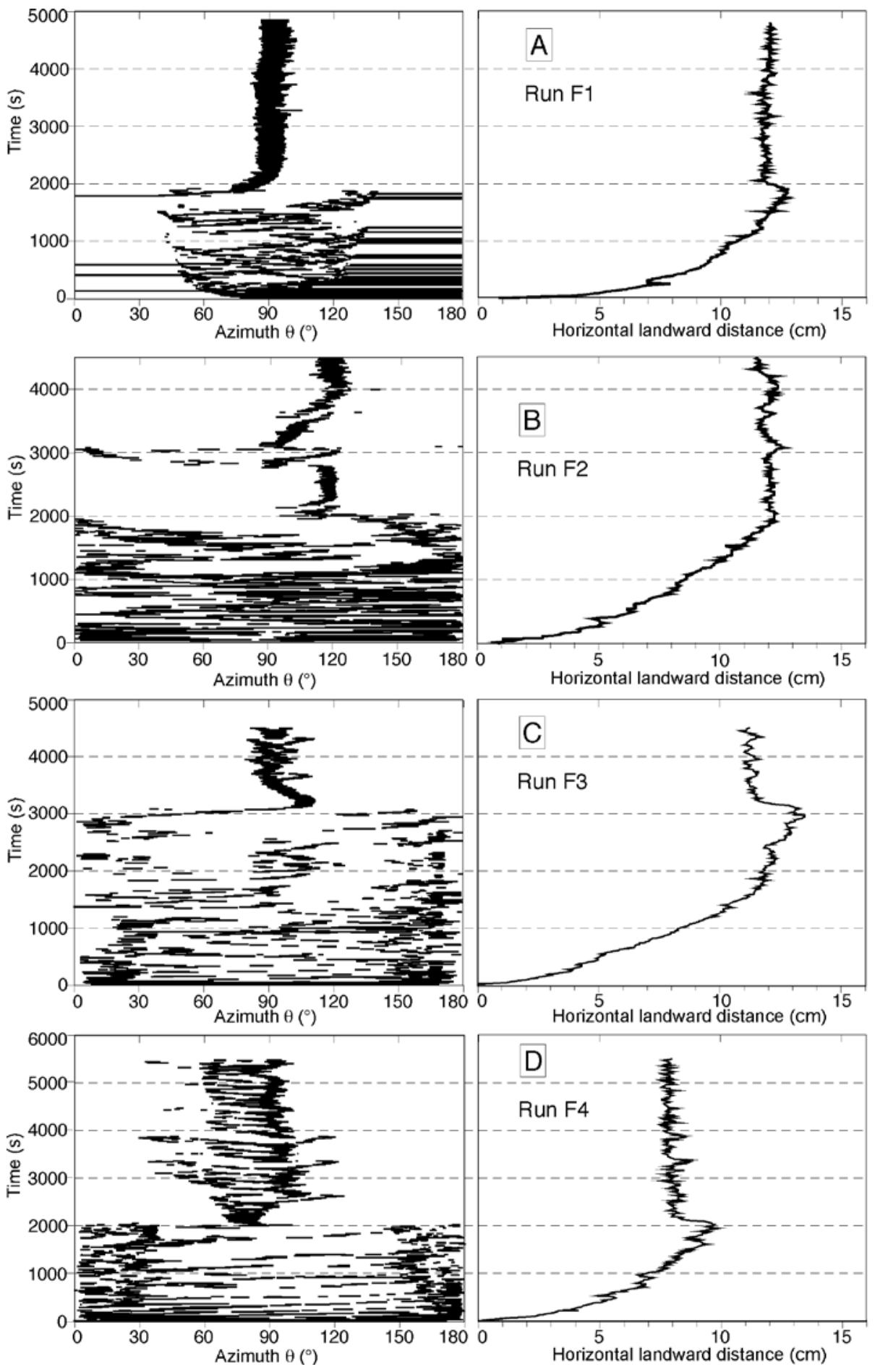
Fig 7
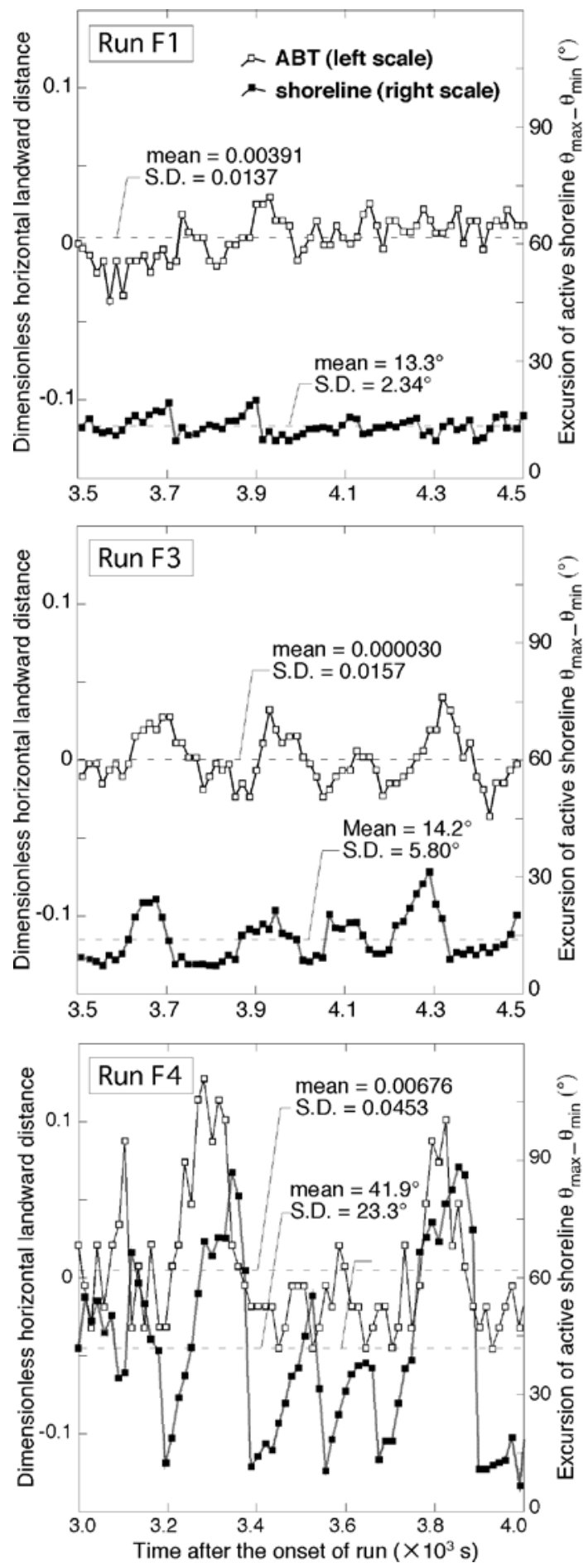
Fig 8

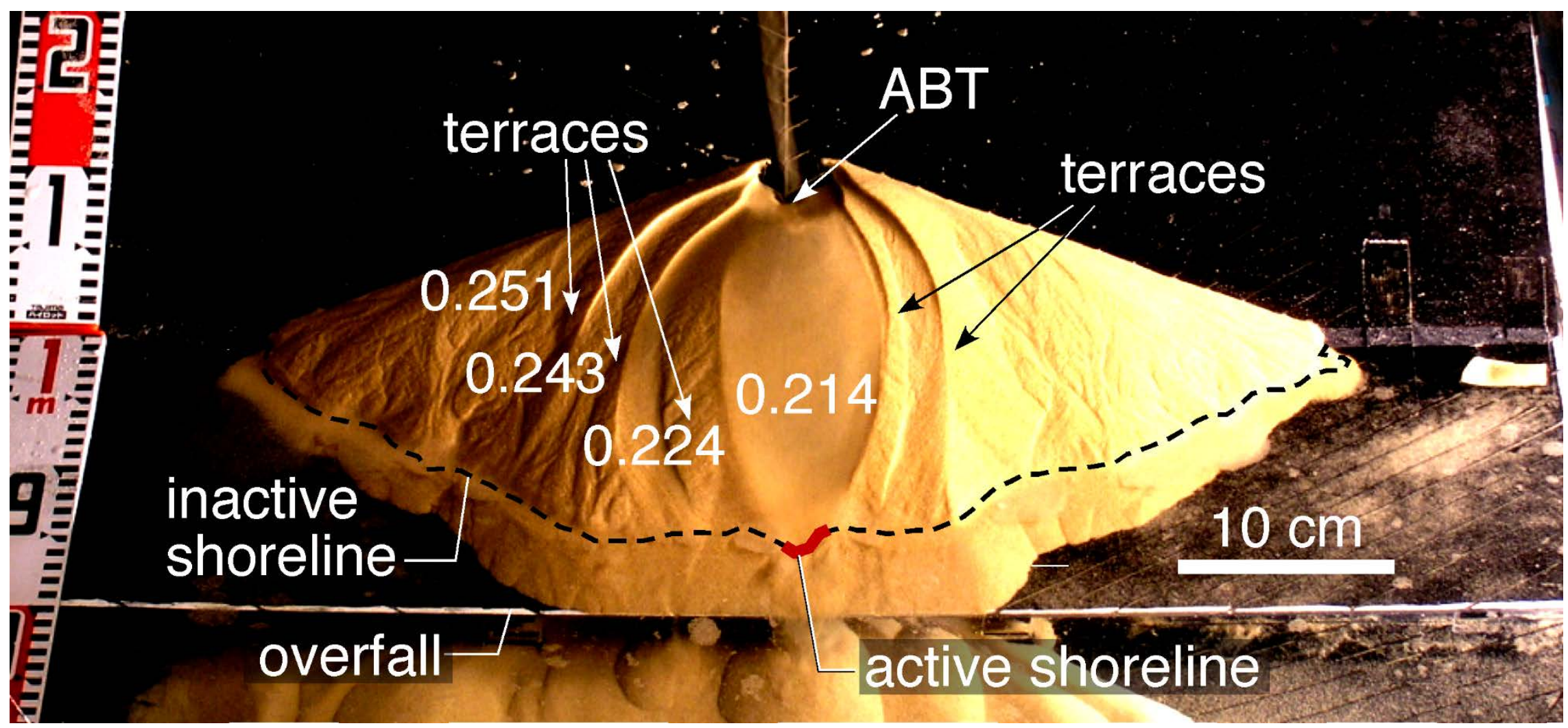


Fig 9

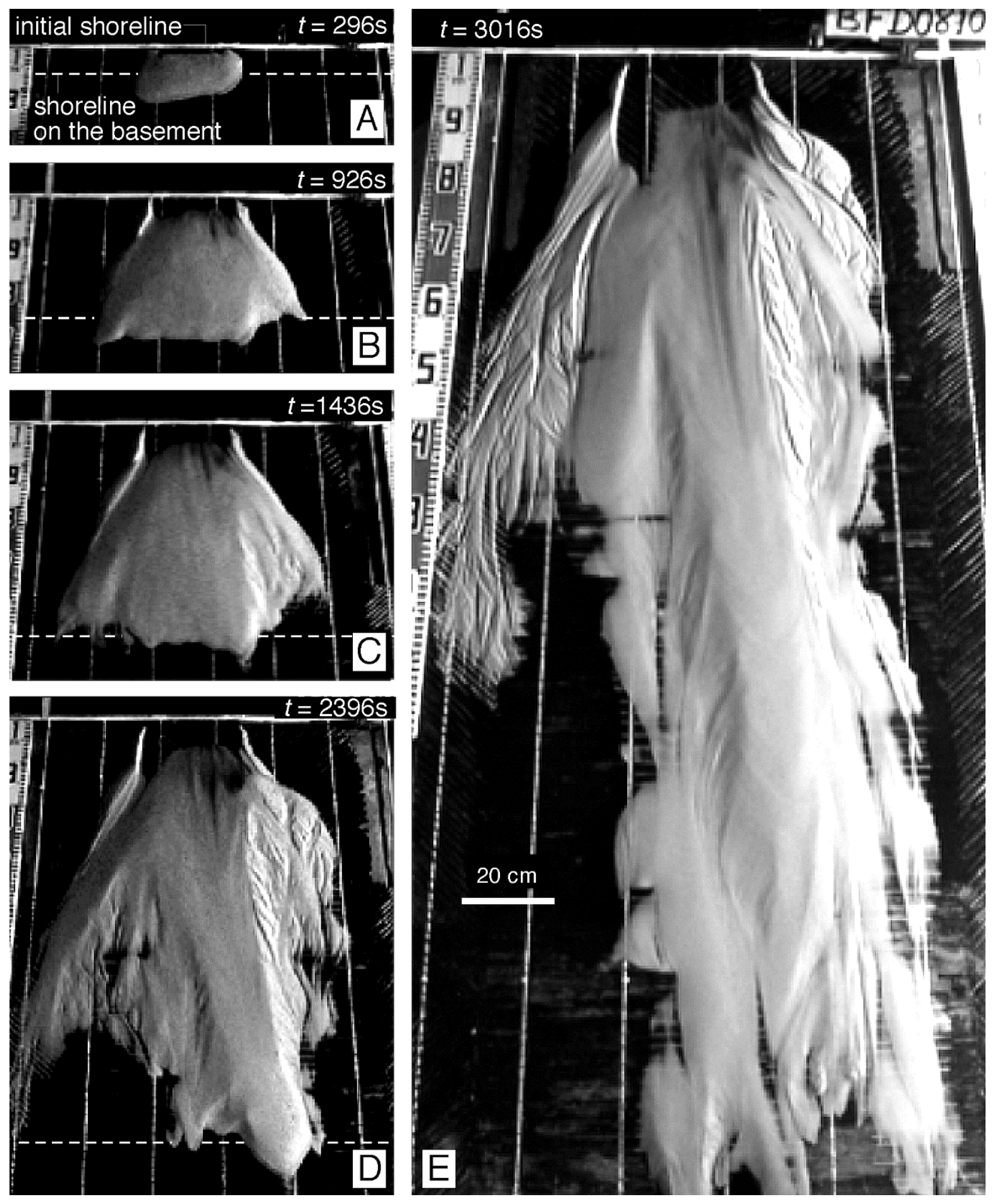


Fig 10
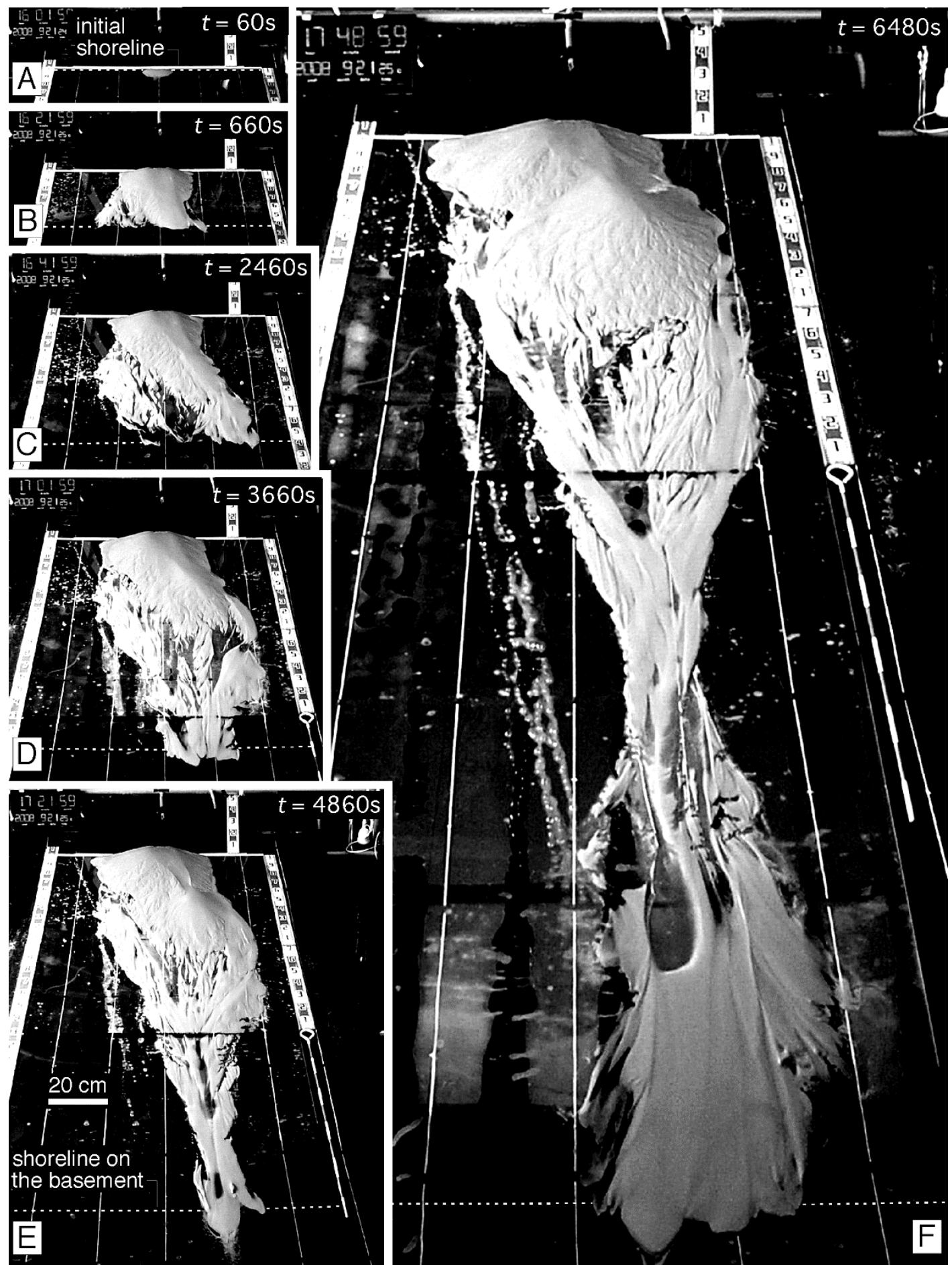
Fig 11
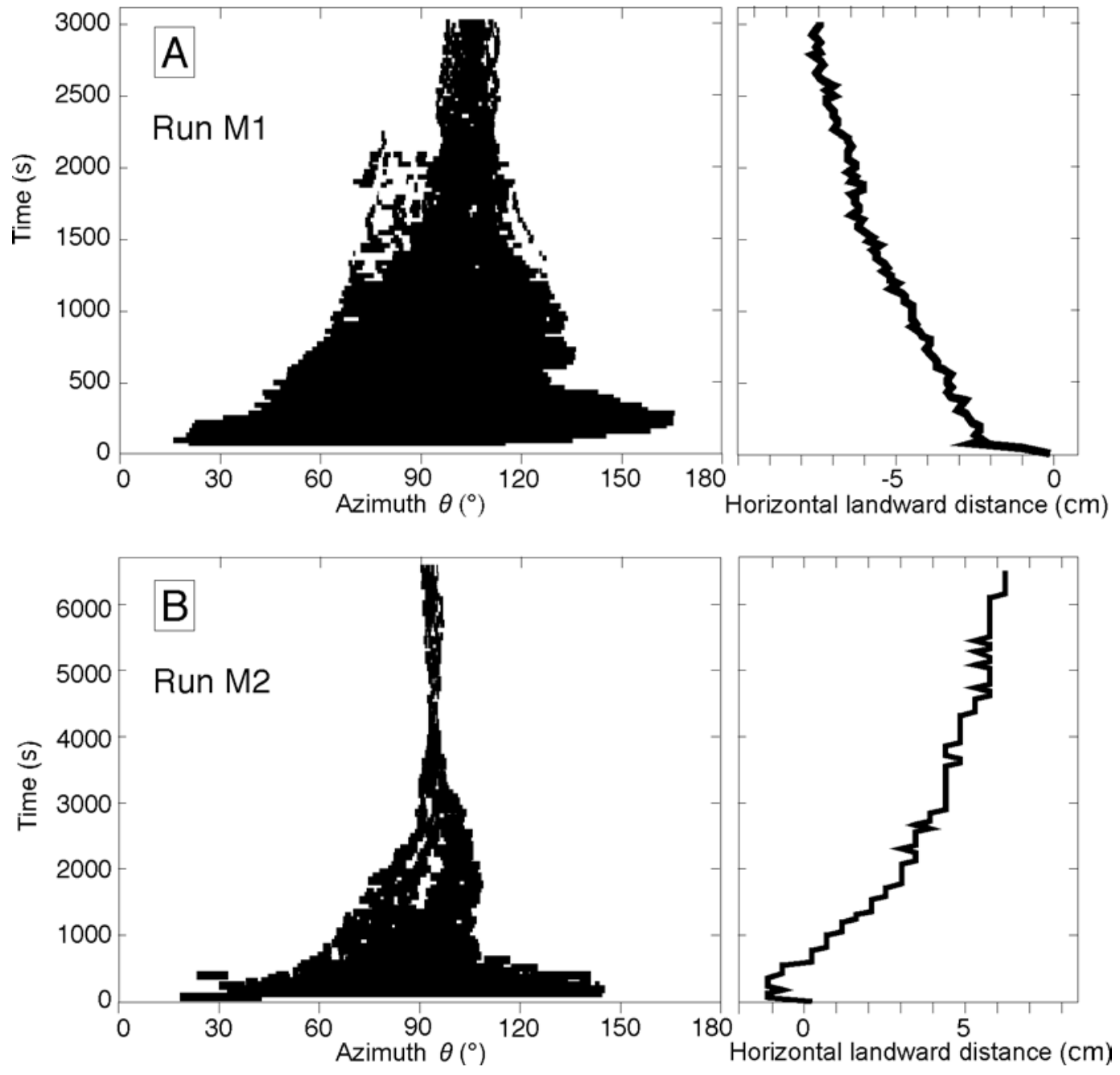
Fig 12

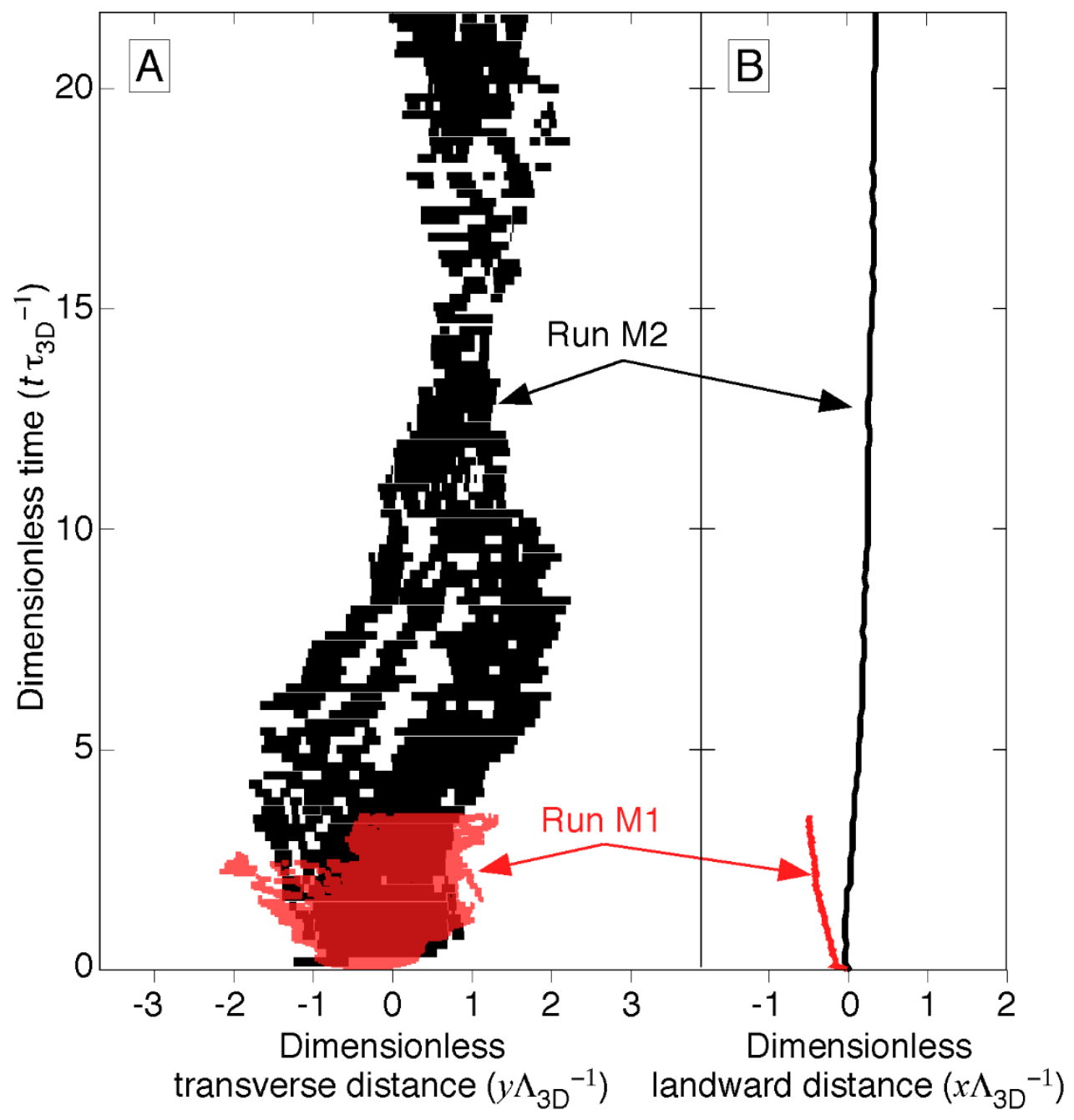


Fig 13

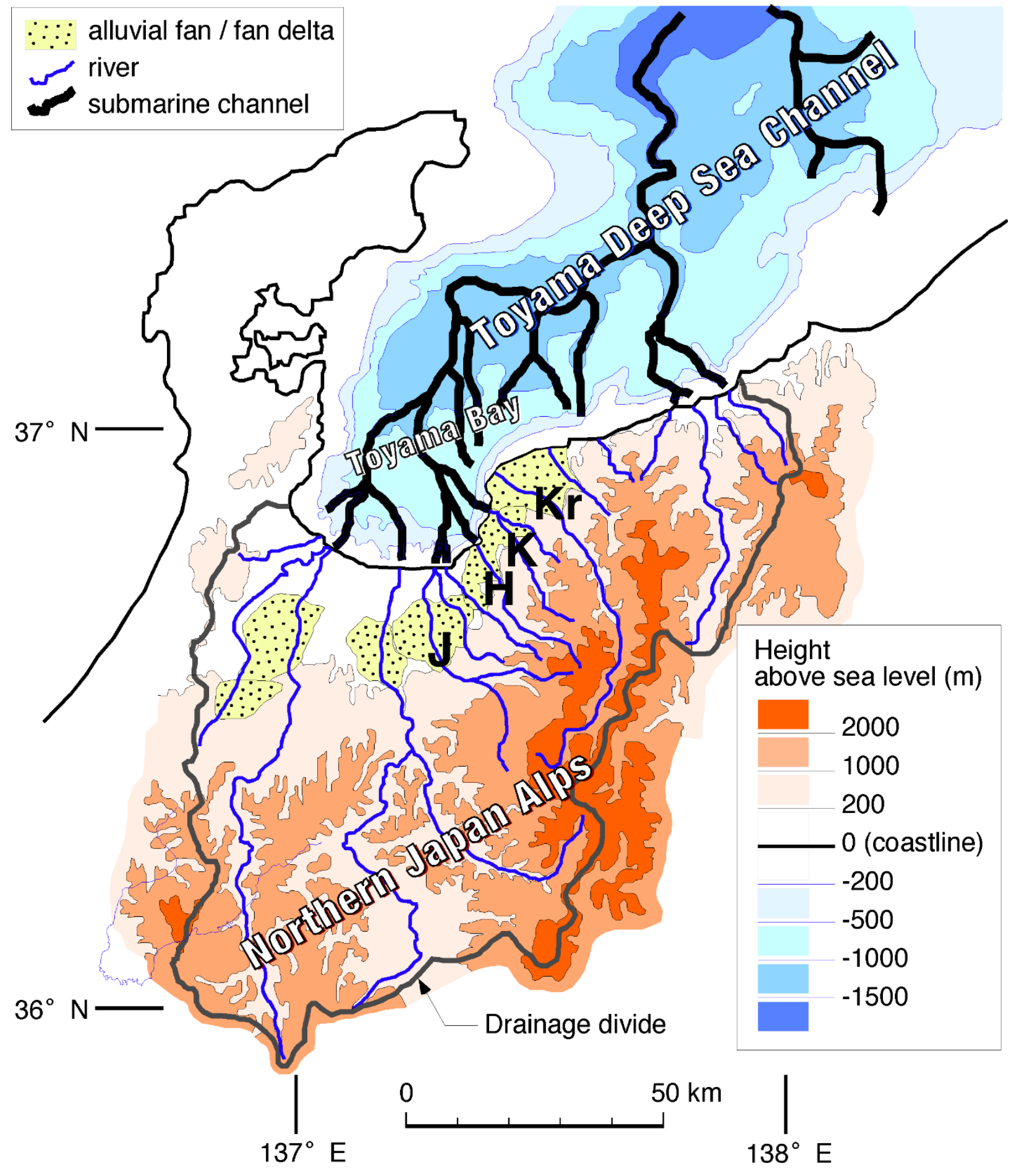


Fig 14

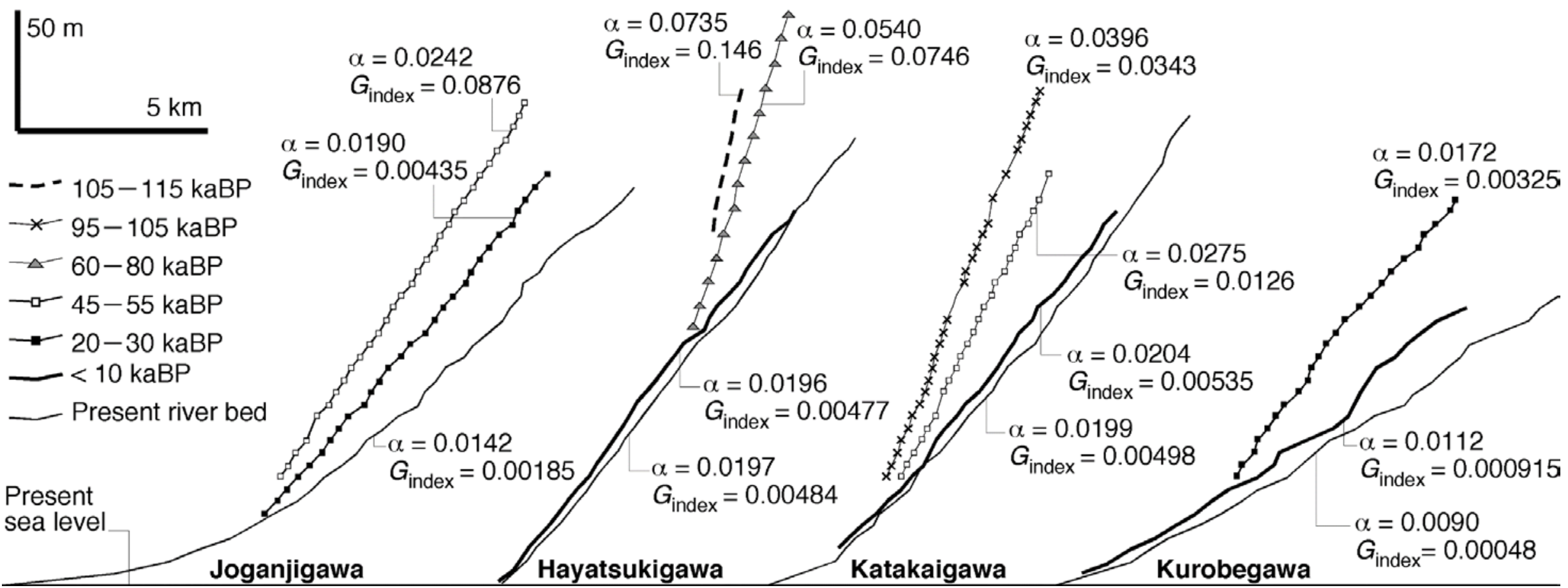




\section{Fig A1}
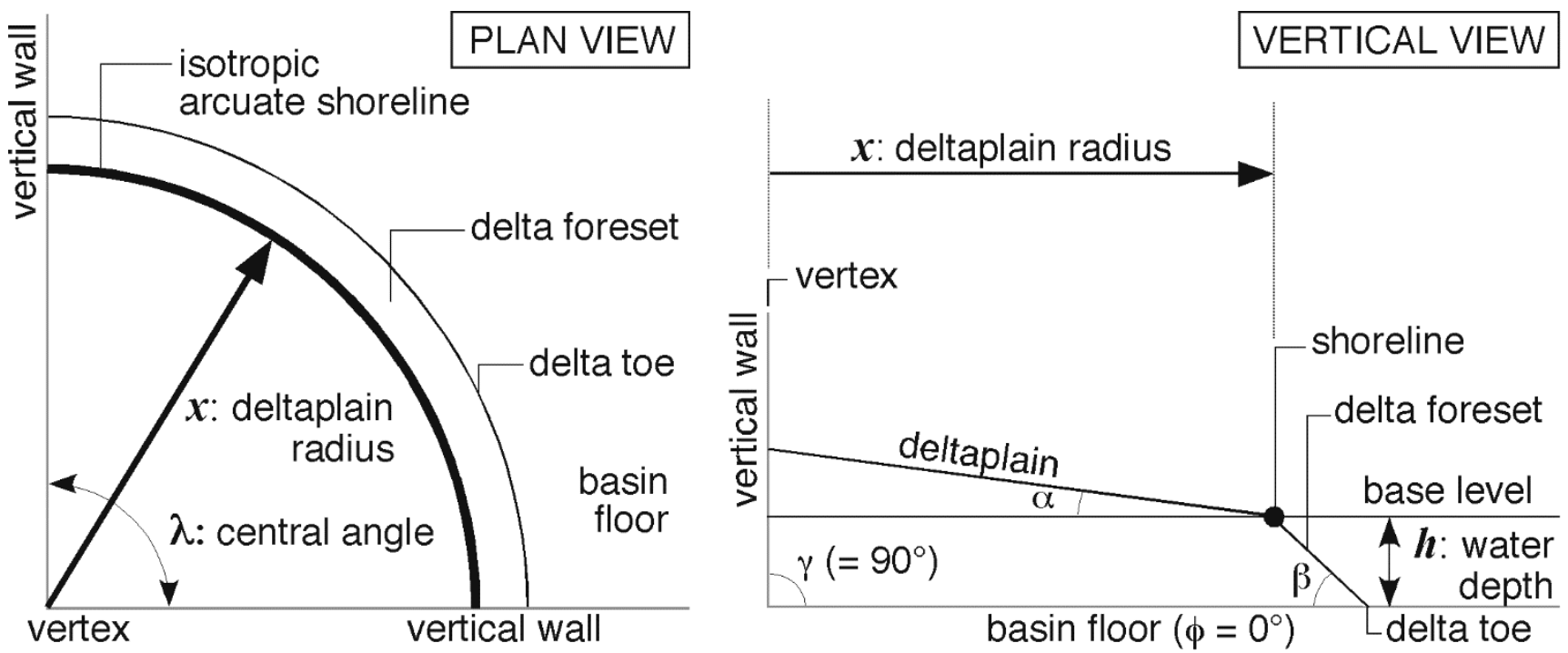
Fig A2

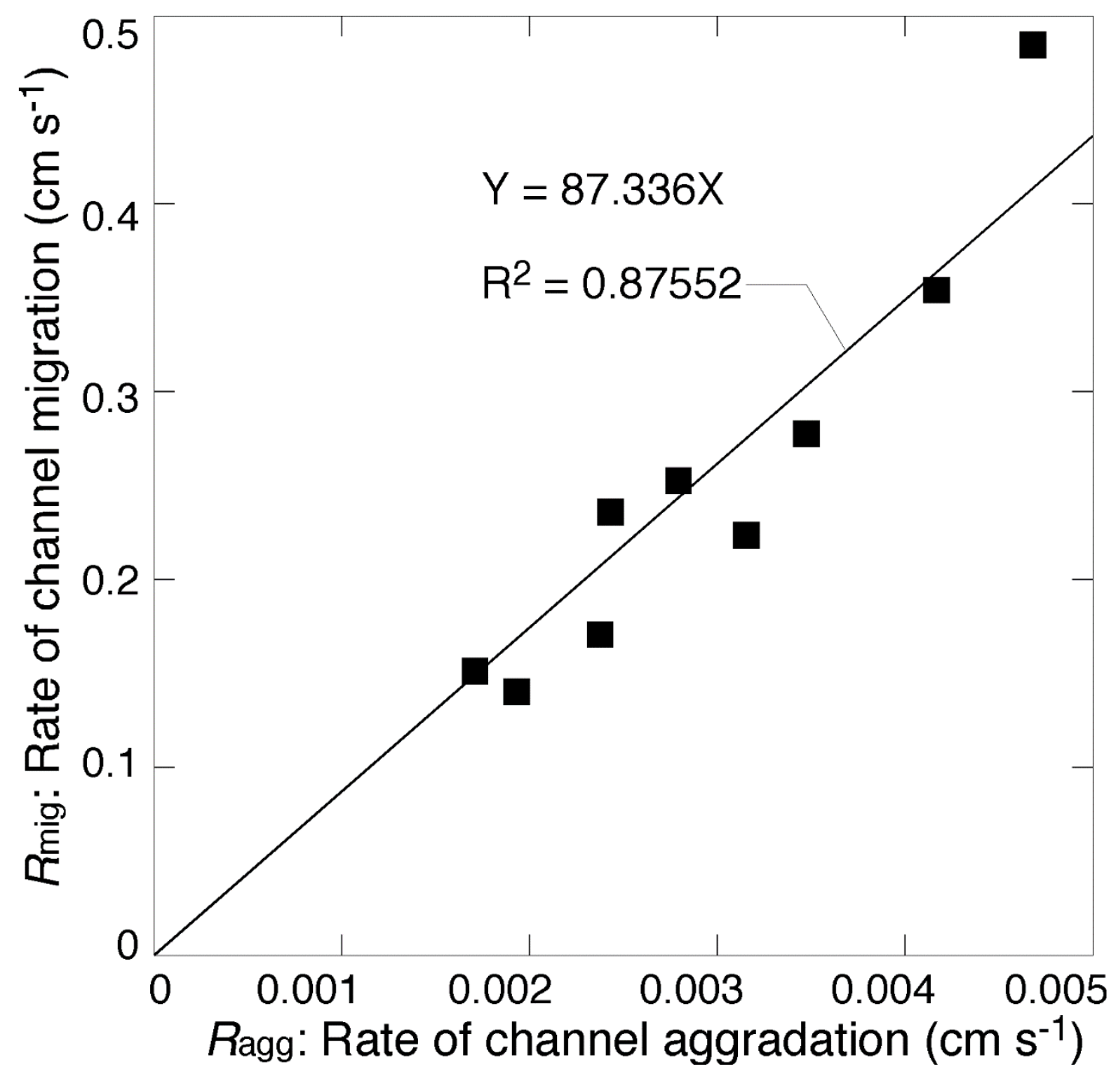


Fig A3
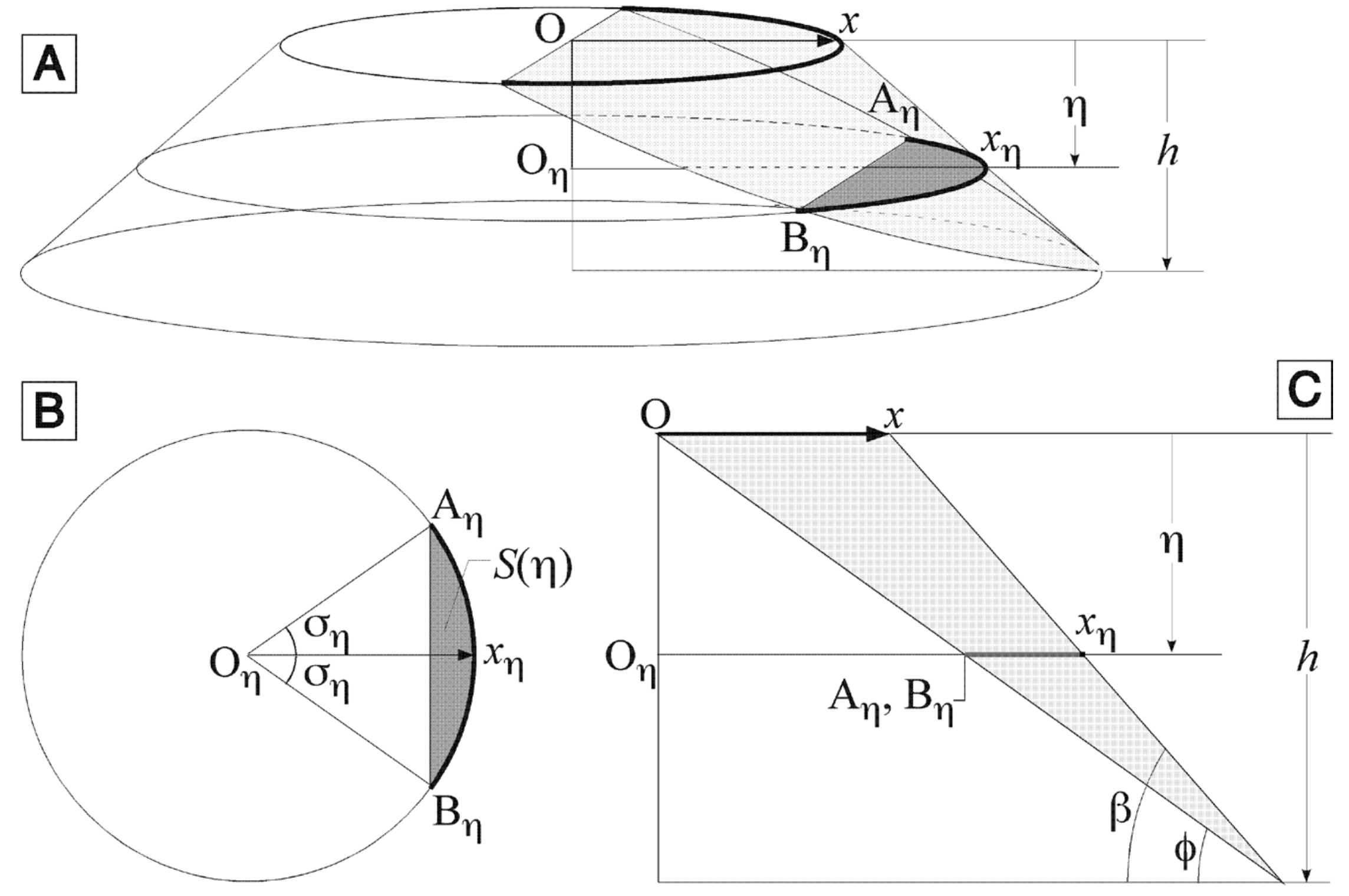